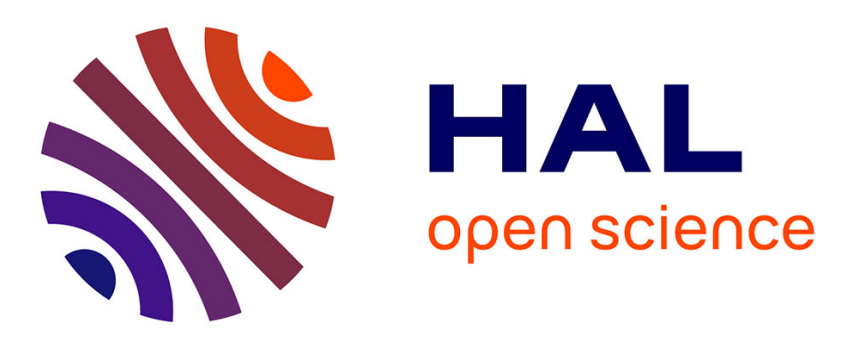

\title{
Complexity of Deep Low-Frequency Earthquake Activity in Shikoku (Japan) Imaged From the Analysis of Continuous Seismic Data
}

Natalia Poiata, Jean-Pierre Vilotte, Nikolai M Shapiro, Mariano Supino, Kazushige Obara

\section{To cite this version:}

Natalia Poiata, Jean-Pierre Vilotte, Nikolai M Shapiro, Mariano Supino, Kazushige Obara. Complexity of Deep Low-Frequency Earthquake Activity in Shikoku (Japan) Imaged From the Analysis of Continuous Seismic Data. Journal of Geophysical Research: Solid Earth, 2021, 126 (11), 10.1029/2021JB022138 . insu-03440845

\section{HAL Id: insu-03440845 \\ https://hal-insu.archives-ouvertes.fr/insu-03440845}

Submitted on 22 Nov 2021

HAL is a multi-disciplinary open access archive for the deposit and dissemination of scientific research documents, whether they are published or not. The documents may come from teaching and research institutions in France or abroad, or from public or private research centers.
L'archive ouverte pluridisciplinaire HAL, est destinée au dépôt et à la diffusion de documents scientifiques de niveau recherche, publiés ou non, émanant des établissements d'enseignement et de recherche français ou étrangers, des laboratoires publics ou privés.

$$
\text { Copyright }
$$




\section{JGR Solid Earth}

\section{RESEARCH ARTICLE \\ 10.1029/2021JB022138 \\ Key Points: \\ Complexity of Deep Low-Frequency Earthquake Activity in Shikoku (Japan) Imaged From the Analysis of Continuous Seismic Data}

- Extensive, homogeneous 4-year catalog of low-frequency earthquakes was derived from continuous data using automated coherency-based method

- Analysis of low-frequency earthquake occurrence patterns quantifies along-strike segmentation and activity clustering and interaction

- Estimation of the front propagation speeds of low-frequency earthquakes activity performed through linear and diffusive patterns

Supporting Information:

Supporting Information may be found in the online version of this article.

Correspondence to:

N. Poiata,

poiata@ipgp.fr

Citation:

Poiata, N., Vilotte, J.-P., Shapiro, N. M., Supino, M., \& Obara, K. (2021). Complexity of deep low-frequency earthquake activity in Shikoku (Japan) imaged from the analysis of continuous seismic data. Journal of Geophysical Research: Solid Earth, 126, e2021JB022138. https://doi. org/10.1029/2021JB022138

Received 30 MAR 2021

Accepted 19 OCT 2021

Author Contributions:

Conceptualization: Natalia Poiata, Jean-Pierre Vilotte, Nikolai M. Shapiro, Mariano Supino, Kazushige Obara Data curation: Kazushige Obara Formal analysis: Natalia Poiata Funding acquisition: Jean-Pierre Vilotte, Nikolai M. Shapiro Methodology: Natalia Poiata, JeanPierre Vilotte, Nikolai M. Shapiro Project Administration: Nikolai M Shapiro

Visualization: Natalia Poiata Writing - original draft: Natalia Poiata

Writing - review \& editing: Natalia Poiata, Jean-Pierre Vilotte, Nikolai M. Shapiro, Mariano Supino, Kazushige Obara

(C) 2021. American Geophysical Union. All Rights Reserved.

\author{
Natalia Poiata $^{1,2}$ (D), Jean-Pierre Vilotte ${ }^{1}$ (D), Nikolai M. Shapiro ${ }^{3,4}$ (D), Mariano Supino ${ }^{1}$ (D), and \\ Kazushige Obara $^{5}$ (D)
}

${ }^{1}$ Université de Paris, Institut de Physique du Globe de Paris, CNRS, Paris, France, ${ }^{2}$ National Institute for Earth Physics, Ilfov, Romania, ${ }^{3}$ Université Grenoble-Alpes, Institut des Sciences de la Terre, CNRS, Grenoble, France, ${ }^{4}$ Schmidt Institute of Physics of the Earth, Russian Academy of Sciences, Moscow, Russia, ${ }^{5}$ University of Tokyo, Earthquake Research Institute, Tokyo, Japan

Abstract We derive an extensive catalog of low-frequency earthquakes (LFEs) in western and central Shikoku applying an automatic, coherency-based detection and location method to 4-year long continuous data from selected seismic stations. Our catalog is the first LFE catalog in this area that does not rely on a priory templates and results from a homogeneous data processing scheme. It allows investigating in detail main characteristics of LFE activity in space and time. We observe clear heterogeneity of the LFE space distribution in the along-strike direction of the subducting Philippine Sea plate corresponding to segments with different sizes, some of which are highly productive in LFE generation. More detailed statistical and correlation-based analysis of LFE occurrence patterns allows quantification of the alongstrike segmentation and examination of the migration and event interaction during the LFE sequences and inter-sequence periods. The analysis indicates that a strong interaction exists among LFE sources during slow slip events, but it otherwise varies significantly among the along-strike segments. We suggest that the observed segmentation of LFE activity is related to static heterogeneity, such as structural property variations along the subduction interface, or dynamic heterogeneity, corresponding to memorydependent stress variations or possible fluid transients. We also confirm that regions with the highest LFE productivity correspond to spots of tectonic tremor triggered by teleseismic earthquakes' surface waves supporting a localized fluid-rich environment with possible fluid transients. Our results illustrate how high-resolution LFE catalog can contribute to the characterization and quantification of slow earthquake processes through detailed statistical analysis of their activity.

Plain Language Summary we build a detailed, four years long, catalog of low-frequency earthquakes (LFEs) in Shikoku, Japan. The catalog is obtained by scanning continuous seismic waveforms recorded at stations in the region with an advanced automatic detection and location method that makes use of the multi-station information of wave arrivals. This leads to a first unbiased, by the previously detected LFEs, extensive catalogue with a large number of events. We further use this detailed catalog, combined with statistical analysis, to study the activity and behaviour of this small noisy events (LFEs), that make part of the slow earthquake family occurring in the Nankai subduction zone. We highlight that the distribution and behaviour in space and time of LFEs is very complex and heterogeneous and find constrained clusters and segments of LFEs that are most probably related to the heterogeneity associated to the complexity of subducting slab structure, stress evolution and possible presence of fluids. Our results highlight that high-resolution LFE catalog can provide new information that may help to characterise and quantify slow earthquake processes and better understand preparation of large events in subduction zones.

\section{Introduction}

In the broad family of observations associated to slow earthquakes occurring in the transition region of subduction zones or active faults, low-frequency earthquakes (LFEs) correspond to short-duration impulsive transient seismic signals (Beroza \& Ide, 2011; Obara \& Kato, 2016; Peng \& Gomberg, 2010). In comparison to regular earthquakes of the same magnitude, LFEs are depleted in high frequency content, characterized 
by dominant frequencies of 1-10 Hz and low signal-to-noise ratio (SNR). Coherent wave arrivals with distinct S- and sometimes P-phases can often be observed at multiple stations, making their detection and location possible (Katsumata \& Kamaya, 2003). LFEs were originally observed in southwestern Japan (e.g., Katsumata \& Kamaya, 2003; Shelly et al., 2006) in the context of tectonic tremor (Obara, 2002) and consequently identified in other subduction zones (Bostock et al., 2012; Brown et al., 2009; Frank et al., 2013; Walter et al., 2011) and along active plate boundary strike-slip faults (Chamberlain et al., 2014; Shelly, 2009; Tang et al., 2010). Complex, minutes to hours long signals of tectonic tremor are today interpreted as a mixture of overlapping in time LFEs occurring in rapid successions or bursts during periods of intense tremor activity (tremor sequences; Shelly et al., 2007b) that are often observed during slow-slip events (SSEs; Bostock et al., 2012; Shelly et al., 2006, 2007b). Later seismic observations at frequencies smaller than $1 \mathrm{~Hz}$ suggested the existence of broadband slow earthquakes (e.g., Masuda et al., 2020). Thus, LFEs can be used as proxy signals to study and characterize tectonic tremors (Frank \& Shapiro, 2014; Kato \& Nakagawa, 2020; Shelly et al., 2007a) or detect low-amplitude short-term SSEs that are missed in geodetic data analysis (Frank, 2016; Lengliné et al., 2017; Rousset et al., 2019). In more general lines, LFEs can be used to estimate the extent and complexity of slow slip phenomena (Kano \& Kato, 2020; Shelly et al., 2007a).

Although it has been widely recognized that slow earthquakes, occurring in transition zones at a downdip portion of the locked seismogenic zone, play an important role in the seismic cycle and preparation of large megathrust earthquakes (e.g., Obara \& Kato, 2016), their generation mechanisms remain poorly understood. Given the volcanic tremor analogy, the initial hypothesis was relating tremor to the fluid-driven seismogenic processes (Kao et al., 2005; Katsumata \& Kamaya, 2003; Obara, 2002). Following studies, pointing at the coincidence between tectonic tremor and slow-slip events (e.g., Obara \& Hirose, 2006; Rogers \& Dragert, 2003; Schwartz \& Rokosky, 2007) and supported by the analysis of tectonic tremor and LFE signals characteristics (Bostock et al., 2012; Frank et al., 2013; Ide et al., 2007; Imanishi et al., 2016; Shelly et al., 2007b), built support for the hypothesis that LFEs are generated by shear slip on the fault. More recent studies (Audet et al., 2009; Audet \& Bürgmann, 2014; Kim et al., 2010; Nakajima \& Hasegawa, 2016; Song et al., 2009) suggest that fluids trapped at the plate interface and, consequently, high pore-fluid pressure, are the main factors in creating weak fault interface necessary for slow earthquakes' generation, and can even play an active role in slow earthquake region and the process itself (Frank et al., 2015; Shapiro et al., 2018).

Tremor and LFE activity is known to exhibit strong segmentation both along dip (e.g., Frank et al., 2014) and strike (e.g., Brudzinski \& Allen, 2007; Maury et al., 2018) of the subducting plate. This spatial heterogeneity is considered to mainly reflect the heterogeneity in the frictional regime (e.g., Obara et al., 2010) or pore-fluid pressure distribution (e.g., Kano et al., 2018; Nakajima \& Hasegawa, 2016) along the deep plate interface. However, details of the long-term global-scale LFE activity in southwest Japan remain poorly understood and lack quantitative assessment. This is due, on the one hand, to the typically limited time-period of analysis, and, on the other hand, to challenges in building well-resolved LFE catalogs not limited to the strongest events or to previously detected event template dictionaries.

In the Nankai subduction zone of southwestern Japan deep tectonic tremors are distributed quasi-continuously, over a total length of about $700 \mathrm{~km}$, within a narrow belt-like zone along the edge of the locked seismogenic region at about 20-40 km depth interval (e.g., Obara, 2002; Obara \& Kato, 2016). The impulsive signals of LFEs are used by Japan Meteorological Agency (JMA) to routinely determine the hypocenters of strongest and/or isolated LFEs with clearly distinguishable S-wave (and if available P-wave) arrivals that can be picked by standard phase-picking algorithms (Katsumata \& Kamaya, 2003). These routinely determined hypocenters are used to monitor temporal changes in the locking state along the Nankai subduction zone. However, the JMA catalog generally misses many events, like those that are occurring during the intense tremor sequences, when complex and highly mixed signals result in a very low SNR which makes it difficult for standard phase-picking and location techniques to extract and locate individual LFEs. Regardless of these challenges, analysis of the tremor (Ide, 2010; Idehara et al., 2014; Obara et al., 2010) and LFE catalogs (Kato \& Nakagawa, 2020; Shelly et al., 2007a) led to the observation that temporal and spatial patterns of LFE and tectonic tremor activity such as recurrence time of tremor episodes, tidal sensitivity, large and small scale migration speeds, and migration patterns change spatially through the tectonic region. These observations are also supported by results from Cascadia, Guerrero, and Costa Rica subduction zones (Frank et al., 2016; Ghosh et al., 2010; Houston et al., 2011; Walter et al., 2011; Wech \& Creager, 2011), the 

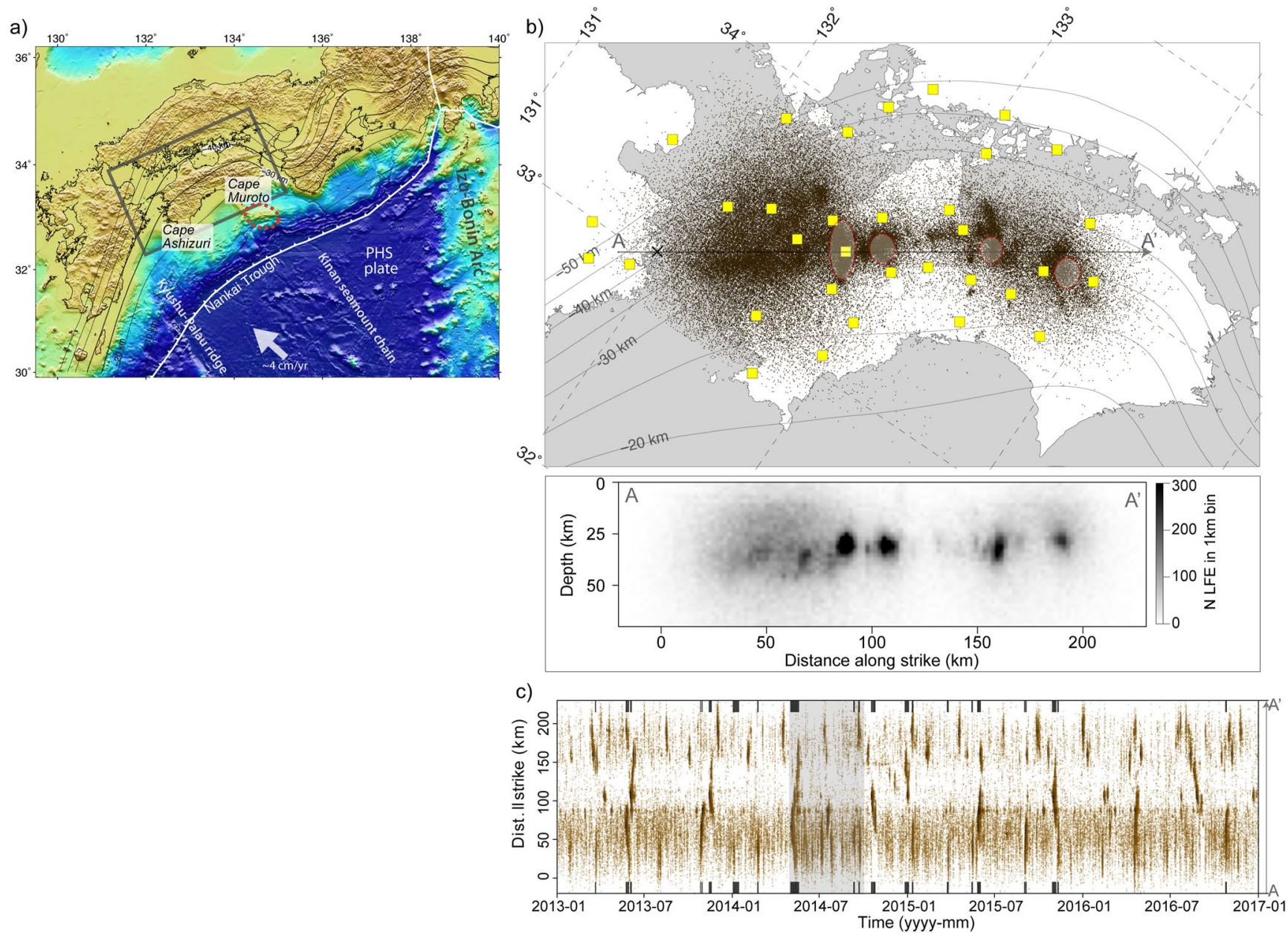

Figure 1. (a) Map of southwest Japan, highlighting the Kinan seamount chain and subducting seamount shown by red dotted oval (Yamazaki \& Okamura, 1989). Dark-gray rectangle indicates the study region. (b) Map view of western and central Shikoku. Brown dots show the location of the automatically detected and located in this study LFEs. Yellow squares indicate the Hi-net National Research Institute for Earth Scienceand Disaster Resilience (NIED) stations used in the study. Thin gray lines are depth contours of the Philippine Sea (PHS) plate top surface derived from the Japan Integrated Velocity Structure Model (Koketsu et al., 2008). Red framed ovals mark the location of the reported triggered tremor (after Chao et al., 2013; Chao \& Obara, 2016; Kurihara et al., 2018; Miyazawa et al., 2008). Lower panel shows a depth section along the A-A' profile, corresponding to the along-strike direction of the subducting PHS slab. (c) Space-time plot of low frequency earthquakes projected along the strike direction of subducting plate (A-A'). Black vertical bars on the upper and lower edges of the plots indicate the timing of short-term slow slip events (SSEs) occurring in western Shikoku according to Advanced Industrial Science and Technology (AIST-SSE) catalog (Itaba \& Ando, 2011; Itaba et al., 2013, 2014, 2015; Ochi et al., 2016). Light-gray rectangle corresponds to Mw 6.2 long-term SSE in the Bungo channel (Ozawa, 2017).

active tremor area along the San Andreas Fault in Parkfield (Shelly \& Johnson, 2011; Shelly, 2015; Trugman et al., 2015) and the Alpine Fault in New Zealand (e.g., Chamberlain et al., 2014).

In this paper, building on the previous work of Poiata et al. (2018) and Supino et al. (2020), we derive a cata$\log$ of LFEs in western and central Shikoku (Figure 1a) by applying the waveform-based automatic method BackTrackBB (Poiata et al., 2016, 2018) to the data covering the period of 4 years (from January 2013 to December 2016) and recorded by a local, high-sensitivity, seismic network. The applied automatic detection and location scheme generates a comprehensive and homogeneous LFE catalog that is not based on an $a$ priory assumption of a template dictionary or manual phase picking. It, thus, potentially explores a wider range of LFE sources than that of JMA or template-based catalogs, which typically are composed of, or built based on (in the case of template-based analysis), a selected subset of LFE sources. We present the resulting automatic catalog and describe its main features. The catalog allows detailed examination of the general space-time characteristics of the LFE activity over the analyzed 4-year time period by applying a detailed statistical and correlation-based analysis to the time-periods of isolated tectonic tremor sequences observed 
SSEs, and those that do not experience slow slip. We further use these results to quantify the segmentation of LFE activity distribution along the strike of the subducting slab and examine the migration, as well as clustering and interaction patterns during the tremor sequences and inter-sequence periods. We attempt to provide a quantitative description of LFE activity clustering and interaction along the strike of subducting slab and confirm that along-strike segments highly productive in LFE generation also correspond to the previously identified spots of tectonic tremor triggered by teleseismic earthquakes' surface waves, supporting a fluid-rich environment and fluid transients in these segments.

\section{Data}

We use the data set of continuous velocity seismograms recorded at selected 29 three-component seismic stations making part of the Japanese national high-sensitivity seismograph network (Hi-net) maintained by the National Research Institute for Earth Science and Disaster Resilience (NIED; NIED, 2019; Okada et al., 2004) and covering the region of western and central Shikoku (Figures 1a and 1b). The Hi-net stations are equipped with a sensor characterized by a natural frequency of $1 \mathrm{~Hz}$ that is installed at the bottom of the boreholes of at least $100 \mathrm{~m}$ in depth providing reduced background noise (Obara et al., 2005). The analyzed continuous waveforms correspond to the time period of 4 years, January 2013-December 2016. For the detection and location of LFEs, we use only horizontal (EW and NS) components of the recordings, owing to the predominance of S-waves in the tectonic tremor signals and observed LFE ground motions pointed by numerous studies (e.g., Maeda \& Obara, 2009; Obara, 2002; Shelly et al., 2006). The detection and location scheme used here, by the design of the signal processing and detection and location steps, exploits only the phase of the signal and the relative variations in its amplitude. As we do not estimate LFE magnitudes, absolute amplitudes of the signal are not used in the study.

\section{Methods}

\subsection{Automatic Detection and Location of LFEs From Continuous Seismic Data}

To build the catalog of LFEs in western and central Shikoku, we applied the automatic full-waveform detection and location method BackTrackBB (Poiata et al., 2016, 2018) to the continuous recordings from the Hi-net stations (Figure 1a). The method makes use of frequency-dependent, statistical characteristic functions (CFs) built from seismic signals, and of a network-based coherency approach to detect and locate in time and space transient events. It proved to be efficient at detecting and extracting impulsive, narrow-band signals from noisy records, such as those associated with LFEs buried in tectonic tremor signals, without requiring previously detected template events (Poiata et al., 2018). The methodological processing steps, as well as the setup parameters, used here closely follow the procedure described in Poiata et al. (2018), which examines a selected tremor sequence in the Shikoku region, in April 2012, and in Supino et al. (2020) which examines LFEs during intense tremor sequences in 2014-2016.

The detection and location workflow of the BackTrackBB method orchestrates a station-by-station signal processing step and a network-based coherency imaging step. The signal processing step builds the time-series of CFs by extracting targeted properties of the continuous non-stationary signals incorporating timefrequency analysis (through multi-band filtering). The CFs are further used in the detection and location step based on the summation of station-pair time-delay estimate functions projected onto 3-D spatial grids of theoretical travel-time differences calculated under the assumptions of a velocity model and a propagating phase. This step builds a coherence function providing the spatial likelihood of source location inside the 3-D grid. Event location in space and time is associated with the maximum of the 3-D coherence function. The method can be adjusted to a relevant waveform feature, such as impulsive short-duration transients, like LFE signals, or longer-duration energy transient components of tectonic tremor by using different CF in the signal processing scheme, such as higher-order statistics (HOS) or energy envelopes, respectively (Poiata et al., 2016, 2018). The automatic detection and location of LFEs in this study are performed by using frequency-dependent kurtosis HOS (4th order moment) CF (kurtosis HOS-CF) in the predominant frequency range of LFEs calculated from the combined horizontal components. This CF is efficient in extracting and picking the onset of short-duration, low SNR (S-wave) signals of LFEs (Poiata et al., 2018). As station selection plays an important role in the detection and location of sources generating weak signals, a preliminary 
step, which corresponds to the detection and location of energy (potential tectonic tremor) sources using the energy envelope CF (Poiata et al., 2016), was implemented in the analysis. This step exploits the fact that the signature of the seismic source over larger distances is more easily observable on the energy envelope as phase information can get blurred by the complexity of propagation path and overlapping signals. It is also supported by the assumption that LFEs and tectonic tremors represent different signatures of the same process, and, thus, during the tremor sequences, have coincident source occurrence in space and time. The preliminary step estimates the location(s) of potential energy or tectonic tremor sources that are further used to select stations for the detection and location of LFEs.

The detailed setup of the automatic detection and location scheme that processes the 4 years of continuous recordings stored as 1-hr long segments with 1 min overlap is following: (a) Defining an optimal station configuration for LFE extraction by detecting and locating potential energy or tectonic tremor sources from the $1 \mathrm{hr}$ long seismograms, using frequency-dependent energy envelope CFs. The CFs are calculated for each station's (combined) horizontal components by applying a multi-band filter of 20 logarithmically spaced narrow-band filters covering the range of $2-15 \mathrm{~Hz}$ and assuming a frequency-dependent decay constant of $0.75 \mathrm{~s}$ for the central frequency (Poiata et al., 2018). Detection and location are performed assuming a sliding window of $180 \mathrm{~s}$ with $140 \mathrm{~s}$ overlap. Source detection is declared each time the maximum value of the coherence function is $\geq 0.9$ (90\%) or when the major axis of the trigger ellipsoid (corresponding to the $68 \%$ confidence ellipsoid fitted to the stacked coherency grid) is $\leq 50 \mathrm{~km}$ and the maximum value of the coherence function is $\geq 0.8$. The estimated locations of potential energy sources for the analyzed hour are then averaged following the clustering scheme of Obara et al. (2010) and assuming that a maximum of two individual sources separated by the minimum distance of $20 \mathrm{~km}$ can be active during the same hour. These hourly single- or double-averaged source locations represent the input for stations selection in the following step. (b) Selection of stations within the radius of $50 \mathrm{~km}$ from the estimated $1 \mathrm{hr}$ (single-o double-) averaged tectonic tremor or energy source location(s). If the number of stations corresponding to this condition is $<5$, the radius is increased to $65 \mathrm{~km}$. (c) Detection and location of LFEs, during the corresponding hours of detected potential tectonic tremor or energy source activity using combined horizontal component kurtosis HOS-CFs and the defined optimal station configuration. The multi-band filtering is performed over the frequency range of $2-15 \mathrm{~Hz}$ with 20 logarithmically spaced narrow-band filters (Poiata et al., 2018). The kurtosis-HOS CF is calculated assuming a frequency-independent decay constant of $2.0 \mathrm{~s}$. In this step detection and location is carried in sliding windows of $20 \mathrm{~s}$ with $18 \mathrm{~s}$ overlap. The detection threshold is set at $0.65(65 \%)$ of the coherence function.

The detection and location step of BackTrackBB requires a predefined setup of potential source locations. We use a 3-D grid that is focused on the deep tectonic tremor belt (implicitly LFEs) in the region of central and western Shikoku (e.g., Obara et al., 2010). The grid is centered at $33.575^{\circ} \mathrm{N}$ and $132.850^{\circ} \mathrm{E}$ with $X$, $Y$, and $Z$ extension of $292 \mathrm{~km} \times 190 \mathrm{~km} \times 100 \mathrm{~km}$ (Figure 1a) and grid interval for the three directions is $1 \mathrm{~km}$. We use the 1-D velocity model of JMA (Kubo et al., 2002) and Grid2Time routine of NonLinLoc (Lo$\max , 2005,2008)$ to calculate theoretical S-wave traveltimes from each of the potential source locations on the 3-D grid to each station. As S-wave is assumed to be the predominant phase of the recorded LFE or tectonic tremor signal (e.g., Obara, 2002; Shelly et al., 2006) it is used for detection and location procedure here.

The described multi-step procedure provides a fully automatic catalog of short-duration, impulsive transient events that, given the selected setup of the detection and location scheme, such as targeted 3-D source volume, selected frequency range, and the S-phase assumption, are expected to correspond to the locations of LFE sources. The catalog can still be contaminated by local earthquakes. However, since, the earthquake activity in the region of western and central Shikoku, corresponding to the tectonic tremor belt targeted in the analysis, is relatively low (e.g., according to the JMA catalog) earthquakes should not have a significant effect on the statistical analysis of the general LFE activity features that will be further analyzed in the paper. In the following section, we present the resulted catalog and analyze the main space and time features of LFE activity. It is worth mentioning that, given the implementation of the BackTrackBB code that includes a parallel version of data processing (see supplement of Poiata et al., 2018), the described LFE detection and location scheme can be easily extended to the (near) real-time analysis of streaming data, offering the possibility for the continuous monitoring of LFE activity. 


\subsection{Analysis of Spatio-Temporal Patterns of LFE Activity}

\subsubsection{Mathematical Representation of LFE Catalogs}

As the result of applying the detection and location scheme described above we obtain a catalog of LFEs that can be mathematically represented as a sequence of points in time and space:

$$
\left(t_{l}, \mathbf{r}_{l}\right), \quad l=1, N
$$

where $t_{l}$ is the time of events occurrence, $\mathbf{r}_{l}$ is the 3-D (latitude, longitude, depth) source position in space of $l-t$ event and $N$ is the total number of LFEs in the catalog. As can be seen in Figure 1b, showing the map of LFE epicenters, most clearly observed feature of event space distribution is variation and segmentation of the LFE distribution along the predominant direction corresponding to the strike of subducting Philipine Sea (PHS) plate. Therefore, we first transform horizontal geographical latitude and longitude $\left(\operatorname{lat}_{l}, \operatorname{lon}_{l}\right)$ coordinates of the LFE epicenters to the local $x y$-Cartesian coordinate system corresponding to the directions parallel and perpendicular to the strike of subducting PHS plate and assumed fixed origin. This strike direction $\theta$ is defined as $\mathrm{N} 40^{\circ} \mathrm{E}$ and zero reference point (origin) is set at $\left(\right.$ lat $_{0}$, lon $\left._{0}\right)$ of $\left(33.00^{\circ} \mathrm{N}, 131.95^{\circ} \mathrm{E}\right.$; Figure 1b). Thus, the coordinate transformation of LFE epicenters will correspond to mapping the original $\left(\right.$ lat $_{l}$, lon $\left._{l}\right)$ coordinates to the $\left(x_{l}, y_{l}\right)$ Cartesian coordinates according to the defined reference point and the counterclockwise rotation by $90^{\circ}-\theta$. This implies that LFE catalog (Equation 1) can be expressed using the along strike distance $x$, the strike perpendicular distance $y$, and depth $z$ as space coordinates. Adding the temporal dimension $t$, the general representation of the transformed catalog becomes:

$$
\left(t_{l}, \quad x_{l}, \quad y_{l}, z_{l}\right), \quad l=1, N
$$

The overall geographic variability of LFE distribution is thus represented by the reduced 2-D catalogs $\left(x_{l}, y_{l}\right)$ and $\left(x_{l}, z_{l}\right)$ shown in Figure $1 \mathrm{~b}$ simplifying the observation of changes in LFE distribution along the strike direction $x$. It is also useful to introduce a reduced space-time catalog $\left(x_{l}, t_{l}\right)$ to represent the main features of the temporal LFE variability along the strike direction of subducting slab. This reduced LFE catalog can be seen as a 2-D point process (e.g., Lowen \& Teich, 2005) represented by a collection, or set, of points located in space and time. One inconvenience with its analysis is that the points are generally irregularly distributed in the space-time domain. To overcome this issue we compute event count functions by discretizing the time-distance plane in regular 2-D bins of size $[\delta t, \delta x]$ centered at $(t, x)$ in time and along-strike. The corresponding 2-D event count function, that is shown in Figure 2a, will be thus represented as:

$$
n_{c}^{\delta t, \delta x}(t, x)
$$

We can also introduce a 2-D event count in the spatial horizontal plane $(x, y)$ (Figure 2b) and 1-D event count in order to characterize the overall LFE variability along strike and in time, respectively (Figures $2 b$ and 2c). These functions will correspond to:

$$
\begin{gathered}
n_{c}^{\delta x, \delta y}(x, \quad y) \\
n_{c}^{\delta x}(x) \\
n_{c}^{\delta t}(t)
\end{gathered}
$$

The transformation of the irregularly sampled in space and time LFE catalog into the regularly sampled event count functions has the advantage of providing a framework in which regular signal processing techniques such as statistical and correlation estimations, as well as Fourier spectral analysis, can be applied. This provides us with the tools to perform a quantitative characterization and classification of LFE activity in space and time.

\subsubsection{Correlation and Characterization of the LFE Activity at Different Spatial Locations Along Strike}

The event count (Equation 3) characterizes the LFE occurrence in time and space (along-strike) dimensions. Fixing the along-strike bin position $x$, we obtain a 1-D time-series of event count function characterizing the time variability of LFE activity at a given space location. In the next step, we quantify the correlation between the LFE activities at different along strike bin locations $(\delta x)$ by computing correlation coefficients 
a)

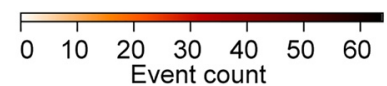

b)
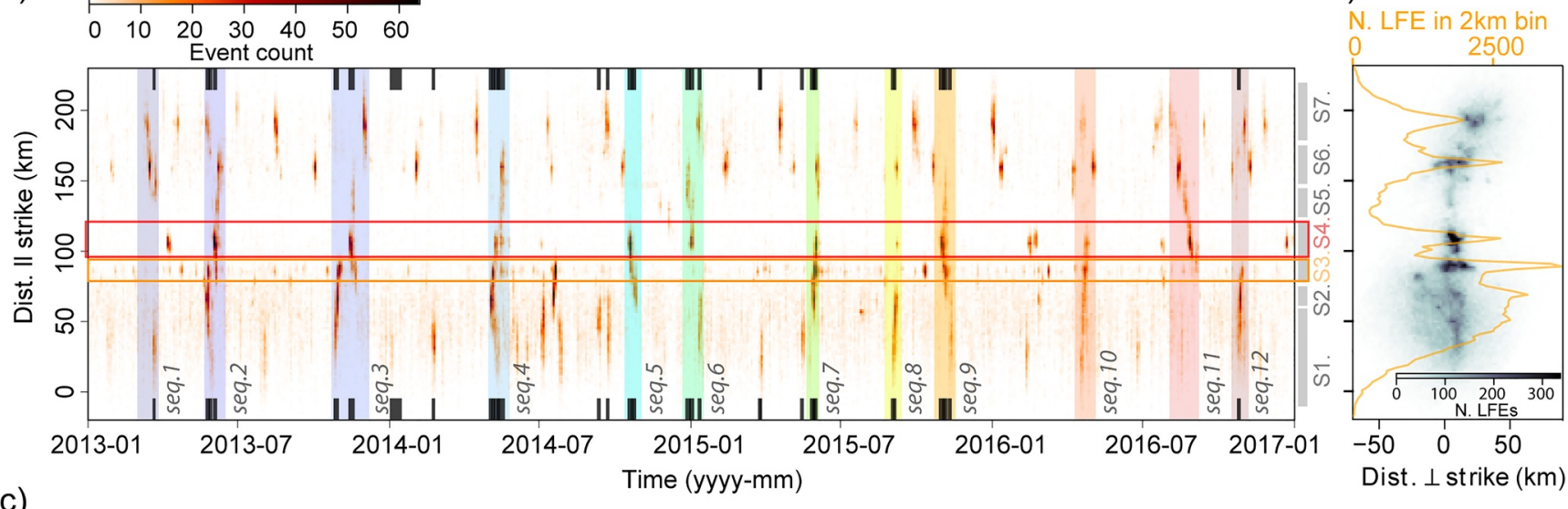

C)

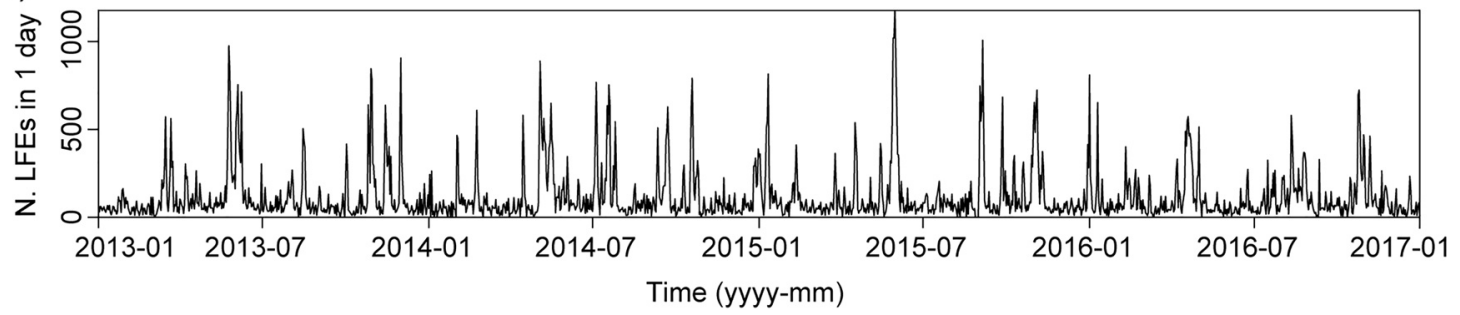

Figure 2. (a) Color coded, 2D space and time low frequency earthquake (LFE) event count representation of LFE catalog calculated in bins [ $\delta t, \delta x]$ of ( 1 day, $2 \mathrm{~km}$ ). Colored rectangles highlight major LFE sequences numbered sequentially. Black vertical bars on the edges mark timing of short-term slow slip events (SSEs) from Advanced Industrial Science and Technology (AIST-SSE) catalog (Itaba \& Ando, 2011; Itaba et al., 2013, 2014, 2015; Ochi et al., 2016), occurring in western Shikoku. Gray shaded bars on the right outline along-strike segments. Orange and red horizontal rectangles mark segments $S_{3}$ and $S_{4}(\mathrm{~b})$ Orange curve: along-strike global event count function showing cumulative number of events in $2 \mathrm{~km}$ along-strike bins for the 4-year catalog. Gray color-coded image shows 2D space LFE event count function. (c) 1D global time-series of LFE event counts for 4-year long time-period.

between these local 1-D event count functions. To account for the possible migration of the activity, we estimate time-delay dependent correlation coefficients. Considering the discrete nature of the count function, these correlation coefficients can be represented as:

$$
\begin{aligned}
& c c\left(x_{l}, x_{k}, m \delta t\right)= \\
& \frac{\sum_{i=1}^{N_{t}}\left(n_{c}^{\delta t, \delta x}\left(i * \delta t, x_{l}\right)-<n_{c}\left(x_{l}\right)>\right)\left(n_{c}^{\delta \delta, \delta x}\left((i-m) * \delta t, x_{k}\right)-<n_{c}\left(x_{k}\right)>\right)}{\sqrt{\sum_{i=1}^{N_{t}}\left(n_{c}^{\delta t, \delta x}\left(i * \delta t, x_{l}\right)-<n_{c}\left(x_{l}\right)>\right)^{2} \sum_{i=1}^{N_{t}}\left(n_{c}^{\delta t, \delta x}\left(i * \delta t, x_{k}\right)-<n_{c}\left(x_{k}\right)>\right)^{2}}}
\end{aligned}
$$

where $N_{t}$ is the number of bins along the $t$ axis, $<n_{c}\left(x_{l}\right)>$ and $<n_{c}\left(x_{k}\right)>$ are mean values of two local 1D event counts, $x_{l}$ and $x_{k}$ correspond to the along-strike bin locations and the tested time delay is a multiple of the time step (bin size) $m \delta t$ with $m$ being an integer. The maximum of Equation 5 over $m$ corresponding to $m^{\text {max }}$, provides the information on time-shifts at which correlation between activities (event count functions) in respective along-strike bins is maximum. These optimal time-shifts and associated maximum correlation coefficients can be expressed as:

$$
\begin{gathered}
\Delta t\left(x_{l}, x_{k}\right)=m^{\max }\left(\left(x_{l}, x_{k}\right)\right) \delta t \\
C C\left(x_{l}, x_{k}\right)=c c\left(x_{l}, \quad x_{k}, m^{\max }\left(\left(x_{l}, x_{k}\right)\right)\right)
\end{gathered}
$$

The above-defined maximum correlation coefficient $C C\left(x_{l}, x_{k}\right)$ estimated for two along-strike LFE event count time series can be used to measure the correlation of LFE activity at different positions along the strike of subducting slab and, thus, their level of interaction. A matrix of correlation coefficients estimated for the entire along-strike region covered by the analysis will represent thus a means to characterize space segmentation of LFE activity observed from the derived 4-year long automated catalog of LFEs. To 
a)

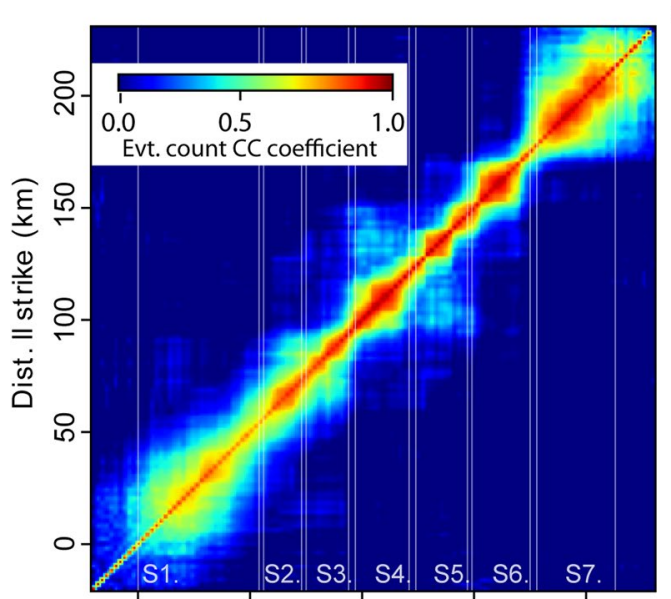

b)

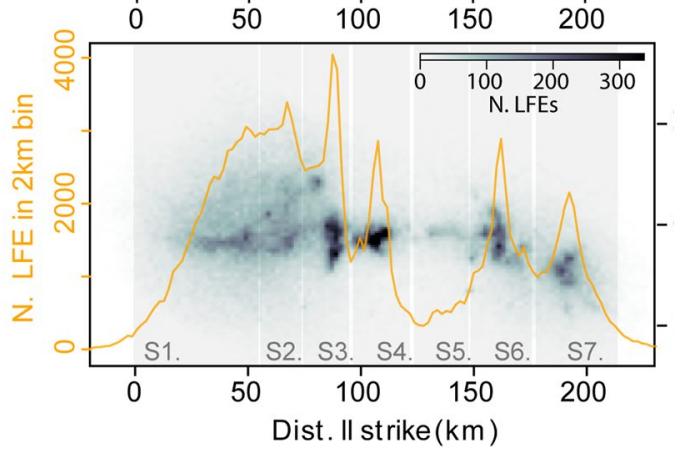

m4 Evt. count $2 \mathrm{~km}$ bin

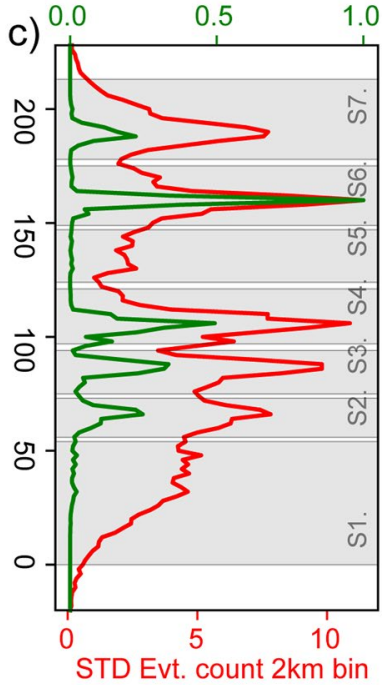

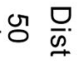

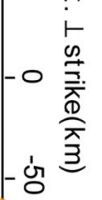

Figure 3. Definition of the along-strike segments (clusters) of low frequency earthquake (LFE) activity in western and central Shikoku. (a) Along-strike correlation coefficient matrix calculated from the 2D space-time event count function. (b) Orange curve: along-strike global event count function showing a cumulative number of events in $2 \mathrm{~km}$ along-strike bins for the 4-year catalog. 2D space LFE event count function, color-coded in gray. (c) Along-strike standard deviation and 4th central moments for along-strike event count functions.

estimate it, we evaluate the maximum correlation coefficients (Equation 6) among the 4-year long event count time-series for all possible along-strike bin combinations $\left(x_{l}\right.$ and $\left.x_{k}, l, k=1, N_{x}\right)$. As we are looking at space correlation at different along-strike locations, we are interested in relatively small time-shifts of correlation coefficients time-series. This will allow accounting for the potential migration of activity between different space locations, at the same time providing information on how related (or similar) the LFE activities of the two along-strike positions are during the all analyzed 4 years. Thus, in Equation 5, variable $m \delta t$ and, implicitly, $N_{t}$ of the summation will span the time-shifts of up to \pm 20 days, based on the assumption of $10 \mathrm{~km} /$ day (e.g., Obara, 2010) as a typical migration speed of tremor sequences observed in the area and knowing that the overall along-strike extent of the analyzed region is of about $200 \mathrm{~km}$. The resulted correlation matrix obtained for our automated catalog is presented in Figure 3a.

To have an additional constrain on the along-strike characteristics of the LFE activity, we used as well statistical metrics such as standard deviation and 4th central moment applied to the along-strike time series of LFE event count functions defined as:

$$
\begin{gathered}
\sigma\left(x_{l}\right)=\sqrt{\frac{\sum_{i=1}^{N_{t}}\left(n_{c}^{\delta t, \delta x}\left(i * \delta t, x_{l}\right)-<n_{c}\left(x_{l}\right)>\right)^{2}}{N_{t}}} \\
m_{4}\left(x_{l}\right)=\frac{1}{N_{t}} \sum_{i=1}^{N_{t}}\left(n_{c}^{\delta t, \delta x}\left(i * \delta t, x_{l}\right)-<n_{c}\left(x_{l}\right)>\right)^{4}
\end{gathered}
$$


where $\sigma\left(x_{l}\right)$ is standard deviation of 1-D event count time-series at along-strike location $x_{l}, N_{t}$ is number of bins along the $t$ axis spanning 4-year time-period, $\left\langle n_{c}\left(x_{l}\right)\right\rangle$ is mean values of 1-D event count and $m_{4}\left(x_{l}\right)$ is 4th central moment of the 1-D event count time-series over the 4-year time-period. These statistical measures provide information about the variation in the LFE occurrence patterns along the strike (Shelly \& Johnson, 2011; Trugman et al., 2015) by characterizing how close the samples of event count time-series are to the Gaussian distribution and, thus, about the stationarity of the activity functions. Comparison of the 4th central moment $m_{4}\left(x_{l}\right)$ and standard deviation $\sigma\left(x_{l}\right)$ calculated for the 1-D 4-year long along-strike event count time series (Figure 2a) are shown in Figure 3c. Combined with the information provided by the correlation matrix, the 1-D along-strike event count functions $n_{c}^{\delta x}(x)$ and 2-D space event count representation $n_{c}^{\delta x, \delta y}(x, y)$ those can be used to define and extract distinct along-strike segments characterized by similar pattern of LFE occurrence over the analyzed 4-year time-period.

\subsubsection{Migration of the LFE Activity in Space}

We focus on estimating large-scale LFE migration front speed for major LFE sequences appearing as alongstrike streaks in the space-time representation of our automatic catalog (Figure 2a). Here, the major sequence is defined as a time-period characterized by intense LFE activity that lasts for over 7-10 days and extends along-strike for at least $\sim 50-100 \mathrm{~km}$, covering a minimum of two defined along-strike segments (Figure 2a). During each of these major LFE sequences, a clear along-strike migration of LFE activity is observed. We make use of the event count representation of the LFE catalog (Equation 3; Figure 2a) and the estimation of correlation coefficients between the 1-D event count functions for fixed along-strike positions (Equations 5 and 6) for evaluating the along-strike migration front speeds of the LFE activity front during the selected major sequences.

The following procedure is applied: we extract the time windows corresponding to the major LFE sequences from the 2-D event count functions (Equation 3; Figure 2a) and compute the correlation coefficients between the 1-D event count time functions (Figures $4 \mathrm{a}$ and $4 \mathrm{~b}$ ) for all (unique) pairs of along strike bins $x_{l}$ and $x_{k}$ as defined by Equation 5. The maximum correlation coefficients, corresponding to the optimal timeshifts for respective strike locations (Equation 6), are used to construct the matrix of correlation coefficients that defines the along-strike similarity of LFE activity (event counts) during the sequence (Figure S3.1c in Supporting Information S1). This correlation matrix is then used for identifying the along strike region that is activated during the sequence and corresponds to the (continuous) highest cross-correlation coefficients $(>0.8$, Figure S3.1c in Supporting Information S1). Further, we use the corresponding correlation coefficient time-shifts (Equation 6) and, assuming the linear LFE activity front propagation, estimate the front migration speed as the slope of the line describing the dependence between the inter-bin distance and the time-shifts using the linear least-square fit approach (Figures $4 \mathrm{a}$ and $4 \mathrm{~b}$ ):

$$
d\left(x_{l}, x_{k}\right)=A * \Delta t\left(x_{l}, x_{k}\right)+B
$$

where $d\left(x_{l}, x_{k}\right)$ is the distance between two along-strike bins and $A=V_{m}$ is LFE front migration speed. Given that for this analysis 2-D event count functions are calculated using relatively coarse space-time bins $[\delta t, \delta x]$ of $[1$ day, $2 \mathrm{~km}]$ and the fact that the LFE activity can be highly complex in selected window, the resulting measurements provide an estimate of the large-scale feature representing the propagation of the activity front. The estimates of the front speed for the analyzed 12 major LFE sequences are summarized in Figure 5. For the sequences characterized by a bilateral propagation of LFE activity, such as, for example, sequence four (Figure 4b), migration speed estimation is performed by fitting the along-strike and back-strike directions of front propagation separately (Figures $2 \mathrm{a}$ and $4 \mathrm{~b}$ ). Each of the LFE sequence time windows starts 2 days prior to the (visually identified) onset of the sequence activity and ends roughly 2 days after its termination. In general, estimating the end of the sequence is more challenging since often clear activity front propagation during the sequence can be followed by a significant, secondary, more diffused activity.

We also investigated the possibility that for some of the LFE sequences front migration can be explained by the diffusive migration pattern, corresponding to the parabolic curve, which is visually observed for some of the tremor sequences (e.g., Figures $4 \mathrm{a}$ and $4 \mathrm{~b}$ ) and was also reported by previous studies (e.g., Ide, 2010; Kato \& Nakagawa, 2020; Kano et al., 2018). This implies that the location of migration front relative to its initiation point follows the square root dependence of time: 
a)

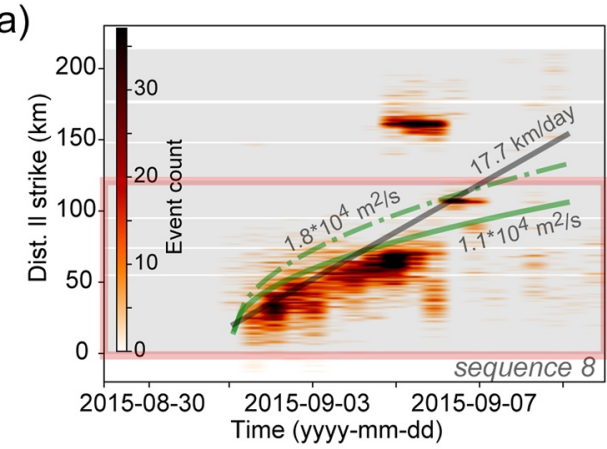

b)

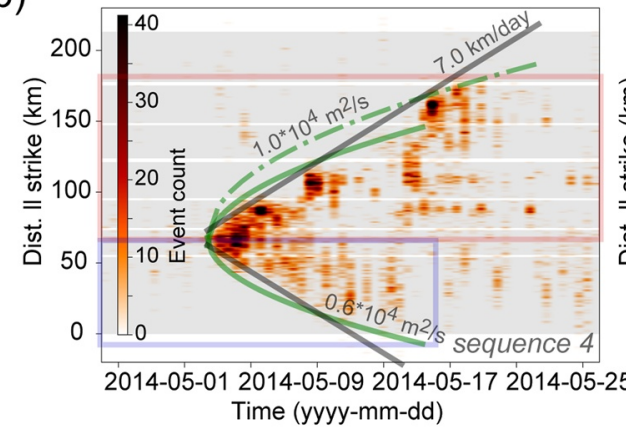

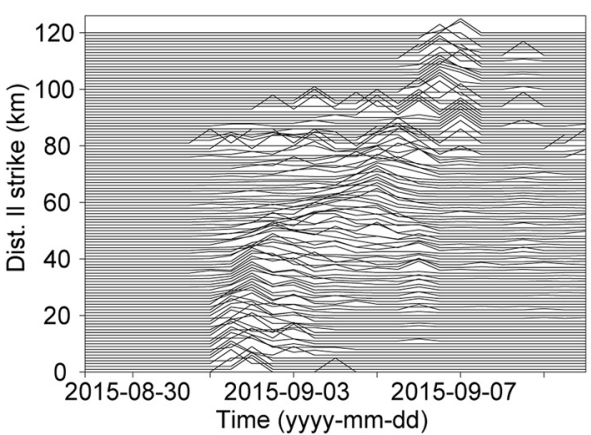
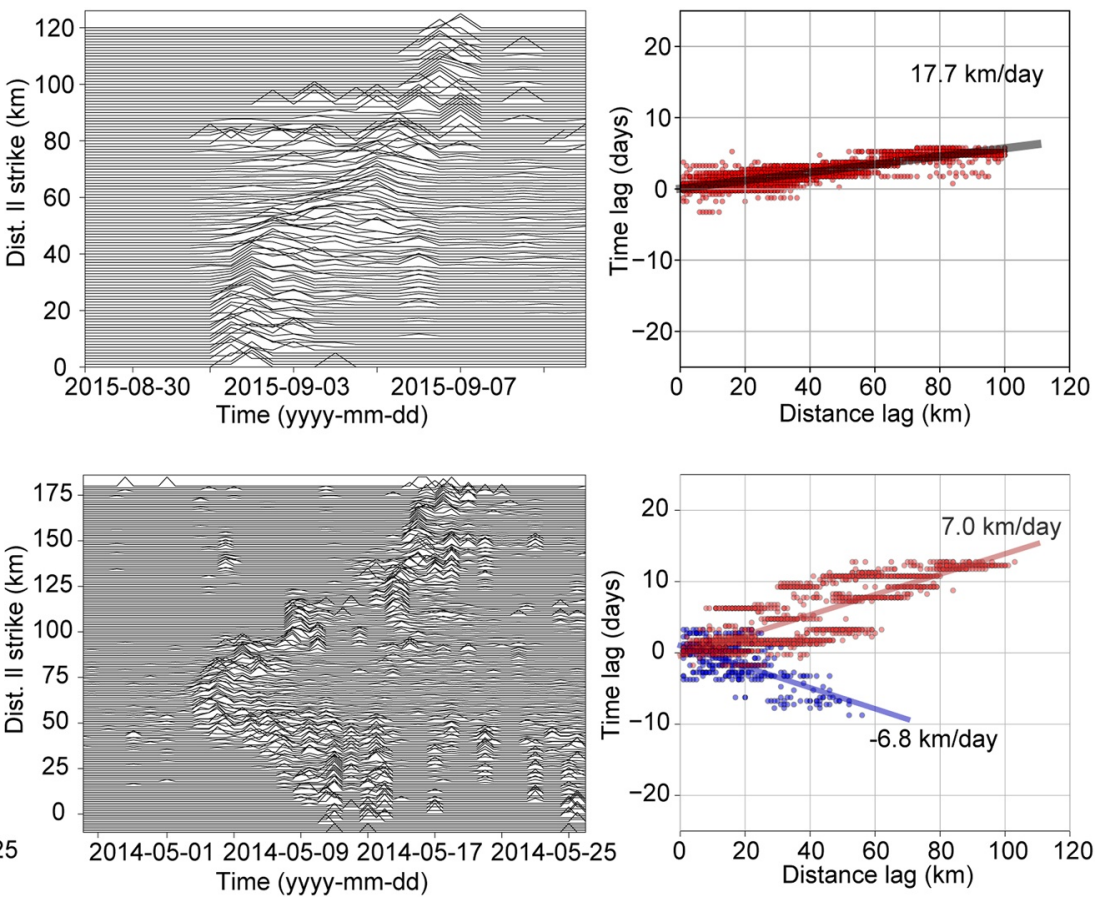

Figure 4. (a) Panels illustrating estimation of the main low frequency earthquake front migration speed for major sequence eight (Figure 2a). Left: 2D spacetime event count function for extracted time-period (color-coded image). Gray rectangles mark along-strike regions, red rectangle contour - the analyzed alongstrike region of sequence space extent. Central: normalized event count functions for along-strike bins plotted as time-series and used for inter-bin time-delay estimations. Right: measurements of time-delay estimates (time lags) obtained from correlation coefficients of along-strike normalized event-count time series (Equations 5 and 6) plotted as the function of along-strike inter-bin distance. Gray line corresponds to linear least-square fit of $17.7 \mathrm{~km} / \mathrm{day}$ migration speed. (b) Same as panel (a), but for major sequence four. Red and blue colors in the plots (rectangle contours, colored dots, and fitted lines) highlight along strike and opposite strike direction activity propagation. Negative value of migration speed correspond to the reverse-strike direction.

a)

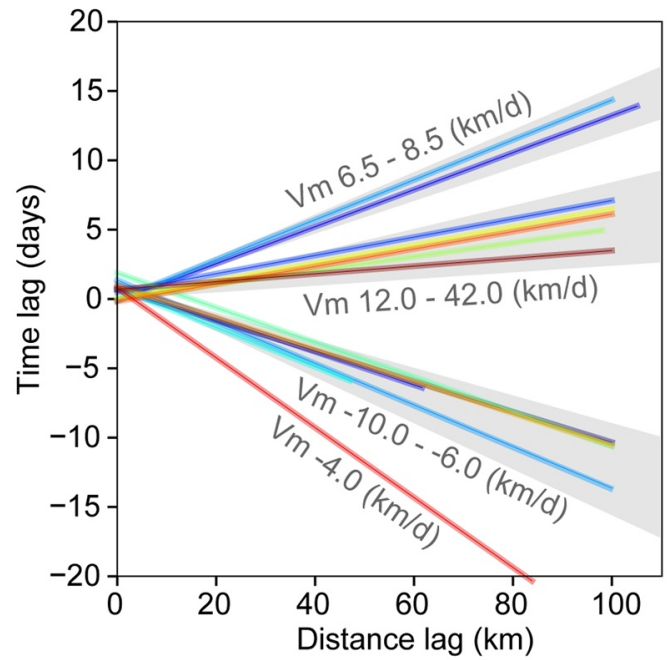

b)

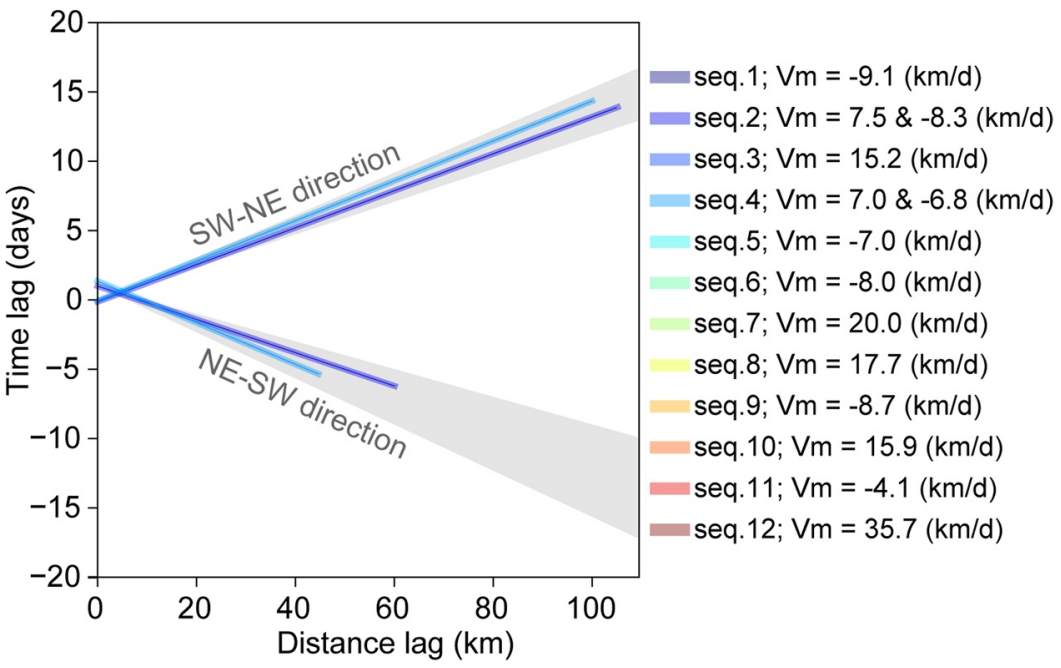

Figure 5. (a) Summary of the along-strike linear migration speed $\left(V_{m}\right)$ estimates for the main front of major low frequency earthquake (LFE) sequences highlighted in Figure 2a and plotted as time-lag as the function of distance lag along strike. (b) Example of migration speed estimates for selected major sequences 2 and 4 showing a bilateral LFE front migration patterns. Color of the line explained in the legend corresponds to the sequence number as presented in Figure 2a. 


$$
d\left(x_{l}\right)=\sqrt{D_{f} * t_{x_{l}}}
$$

where $d\left(x_{l}\right)$ is distance from the sequence initiation point to the along-strike location $x_{l}, t_{x_{l}}$ - the time it takes LFE front to reach $x_{l}$ location and $D_{f}$ - diffusivity constant. To evaluate the diffusivity coefficient for the sequences showing potential diffusive pattern (Figures $4 \mathrm{a}$ and 4b, Figure S3.2 in Supporting Information S1), we fit the parabolic function (Equation 9) to the points corresponding to the maximum of 1-D event count function of the extracted LFE sequence time window for each along-strike bin location $x_{l}$. Example of fits and resulted diffusivity values are summarized in Figure S3.2 in Supporting Information S1. We also evaluate through the forward modeling, adjusting the diffusivity values resulted from the above fit, which diffusivity coefficients would better describe the propagation of the LFE front initiation points for the entire (along-strike) extent of the sequence. The results of this forward diffusivity propagation front calculations are presented in Figures $4 \mathrm{a}$ and $4 \mathrm{~b}$.

\subsubsection{Time-Clustering and Interaction of the LFE Activity}

The statistical tool used for the quantitative characterization of the temporal clustering of LFE activity within the defined along-strike segments relies on point process formalism (e.g., Lowen \& Teich, 2005). We closely follow the scheme proposed by (Frank et al., 2016) for studying temporal clustering of LFE template families along the Mexican subduction zone in Guerrero and later applied to the analysis of volcanic seismicity (Frank, Shapiro, \& Gusev, 2018) and crustal seismicity in the Alps (Beaucé et al., 2019). Under this framework, clustering represents the dependence of event's time occurrence on previous and following events. Each LFE source segment (in our particular case) is considered a discrete point process that generates events whose timing is controlled by an underlying statistical distribution. A burst of events, for example, can be non-clustered, corresponding to an accelerated event rate with random timing following Poisson distribution. Characteristics of the event clustering can vary significantly from Poisson occurrence to collective time clustering depending on the state and properties along the active fault.

The approach for quantifying the degree of temporal clustering is based on the characterization of the time series of event counts (Equation 3), which, in this case, represent the activity of an extended along-strike segment (defined following the procedure in Section 3.2.2) having distinct characteristic behavior of LFE activity. We note such event count:

$$
n_{c}^{\delta t, \delta x}\left(t, x_{s k}\right)
$$

with $x_{s k}$ indicating a particular along-strike segment. The characterization of temporal clustering is further performed by estimating the auto-correlation and power-spectrum of $n_{c}^{\delta t, \delta x}\left(t, x_{s k}\right)$. For an homogeneous Poisson process for which events occur randomly in time at a constant rate and there is no correlation between events, the auto-correlation function of event counts $\left(A C C_{n_{c} t, \delta x}\left(x_{s k}, m \delta t\right)\right)$ corresponds to a Dirac at zero lag times $(m \delta t$, at $m=0)$. The Fourier transform of auto-correlation function gives the power spectrum $\tilde{n}_{c}^{\delta t, \delta x}\left(f, x_{s k}\right)$ which, in this case, will be flat over all frequencies $f$. Presence of temporal clustering between the events, on the other hands, implies temporal correlation of event occurrence in the auto-correlation function at non-zero lag times. It is observed that clustered earthquakes (e.g., Beaucé et al., 2019; Kagan \& Jackson, 1991) or LFE sequences (Frank et al., 2016; Trugman et al., 2015) correspond to scale-invariant time-clustering exhibiting power-law dependence of event count power spectrum on frequency: $\tilde{n}_{c}^{\delta t, \delta x}\left(f, x_{s k}\right) \propto f^{-\beta}$. The strength of temporal clustering can be thus quantified by measuring the clustering coefficient $\beta$ from the slope of the spectrum in log-log space. This estimation is performed by fitting a linear function to the auto-correlation Fourier amplitude spectrum and frequency (or period) values in the log-log space:

$$
\begin{aligned}
\log \left(\mathcal{F}_{\mathcal{A}}\left(A C C_{n_{c}^{\delta t}, \delta x}\left(x_{s k}, m \delta t\right)\right)\right) & =A * \log (T)+B \\
A C C_{n_{c}^{\delta l, \delta x}}\left(x_{s k}, m \delta t\right) & =\sum_{i=1}^{N_{t}}\left(n_{c}^{\delta t, \delta x}\left(i * \delta t, x_{s k}\right) n_{c}^{\delta t, \delta x}\left((i-m) * \delta t, x_{s k}\right)\right) \text { and } A=\beta
\end{aligned}
$$


a)

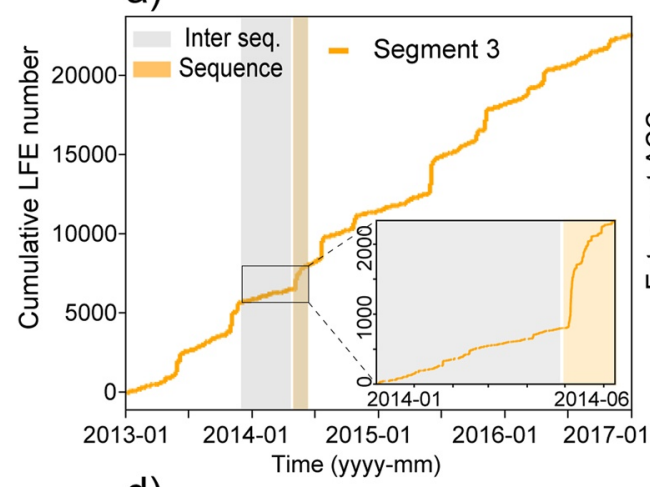

d)

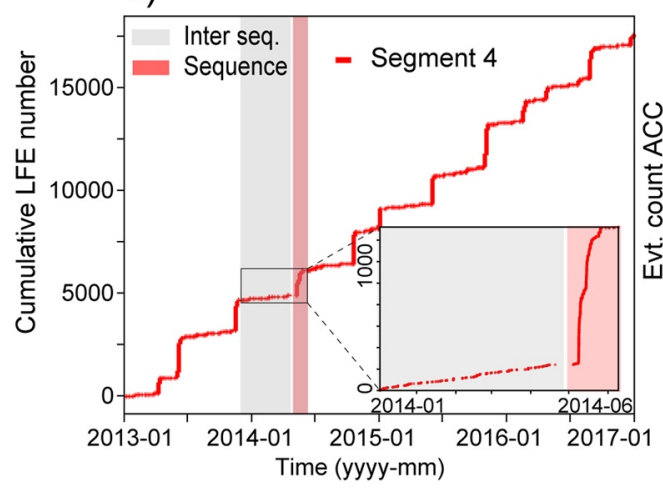

b)

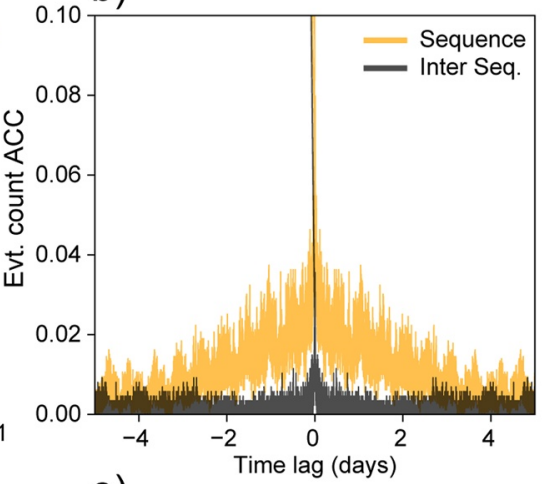

e)

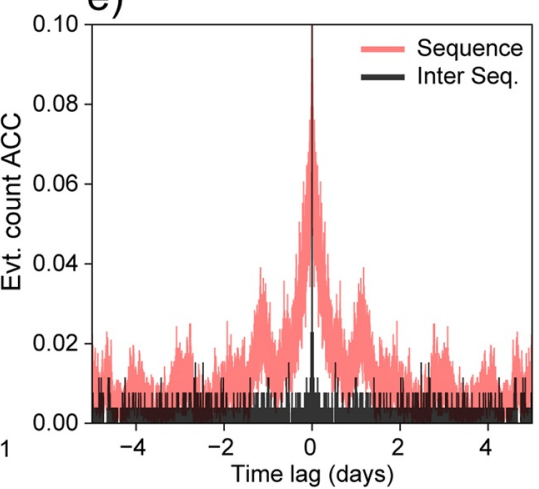

C)
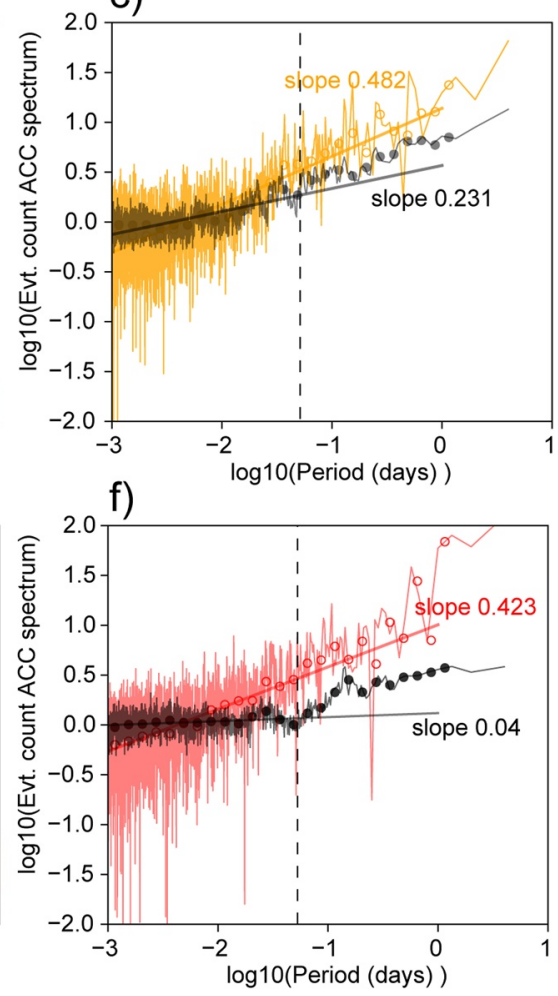

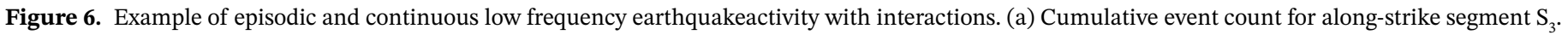

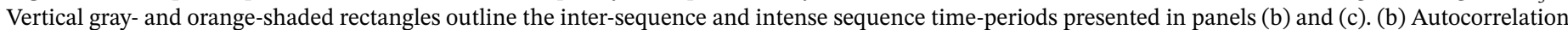

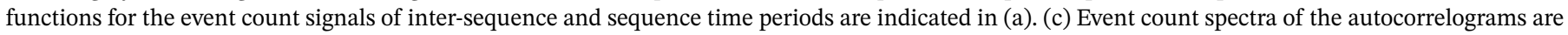

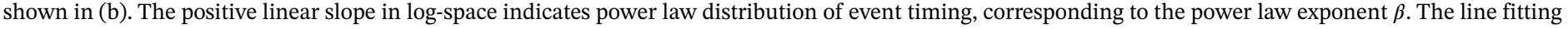

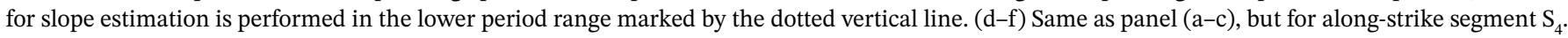

were $\mathcal{F}_{\mathcal{A}}\left(A C C_{n_{c} \delta, \delta x}\right)$ corresponds to Fourier amplitude spectrum of event count auto-correlation function and slope $A$ provides the clustering coefficient $\beta$. We selected to use period $T$ instead of frequency $f$ for spectral domain representation for a more straight-forward relation to the time-domain in which we represent the LFE catalog.

Following the above, a strongly clustered LFE sequence will correspond to large $\beta$ whereas sequence close to a Poisson-like event occurrence will have small $\beta$, and $\beta=0$ will correspond to a homogeneous Poisson process. In general, we expect that LFE activity could be strongly clustered during the periods corresponding to the major slow-slip events or short-term SSEs (Frank, 2016; Frank, Rousset, et al., 2018; Idehara et al., 2014). Characteristics of the event clustering in the inter-slow-slip period can, on the other hand, vary significantly from random (Poisson) occurrence to collective time-clustered depending on the state and properties along the active fault.

We first apply the presented analysis scheme to the event counts corresponding to the time-windows of an intense LFE sequence and inter-sequence interval and selected along-strike LFE segments with distinct activity characteristics (Figure 6). This allows us to test the hypothesis and tune the parameters. Further, analysis is extended to the 4-year long event count functions of the selected along-strike LFE segments, estimating the value of $\beta$ coefficient in sliding windows of 20 days with 5 days overlap (Figure 7) and providing information about the time variation of the temporal clustering of LFE activity during the analyzed 4-year time-period. 
a)

b)
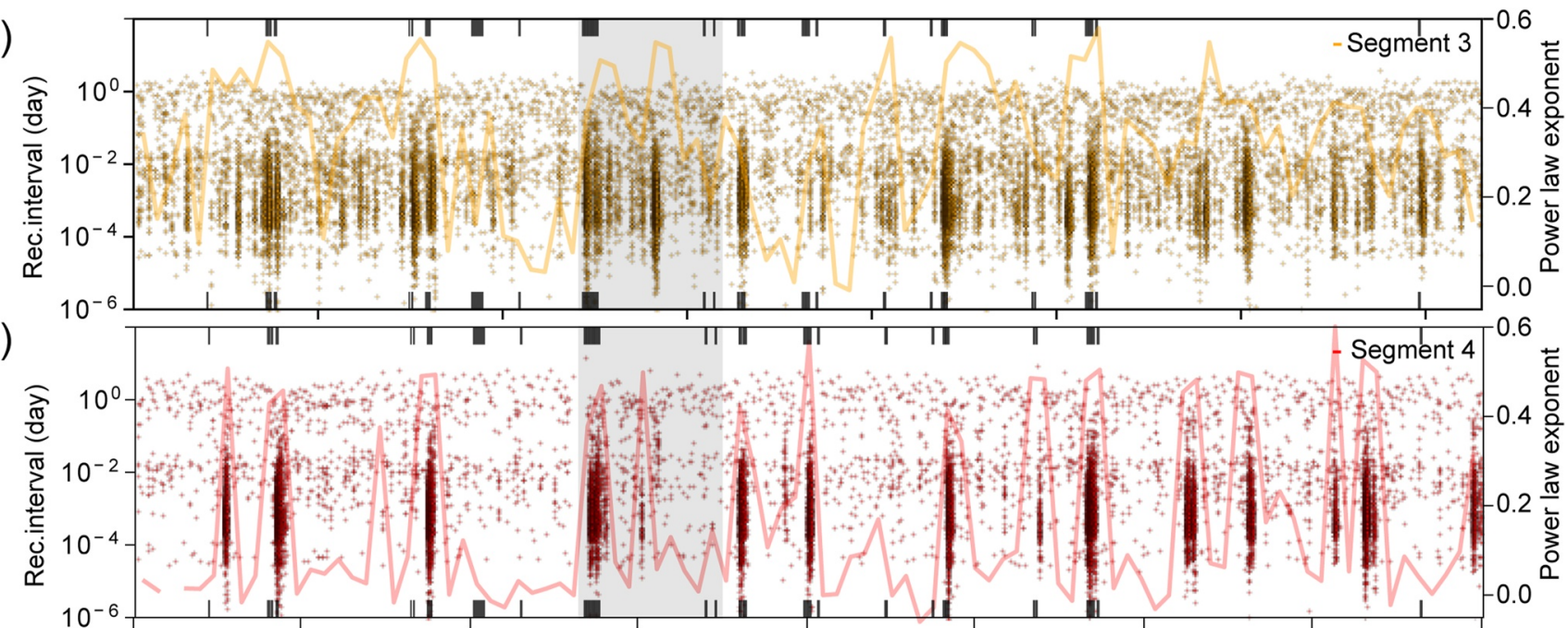

c)

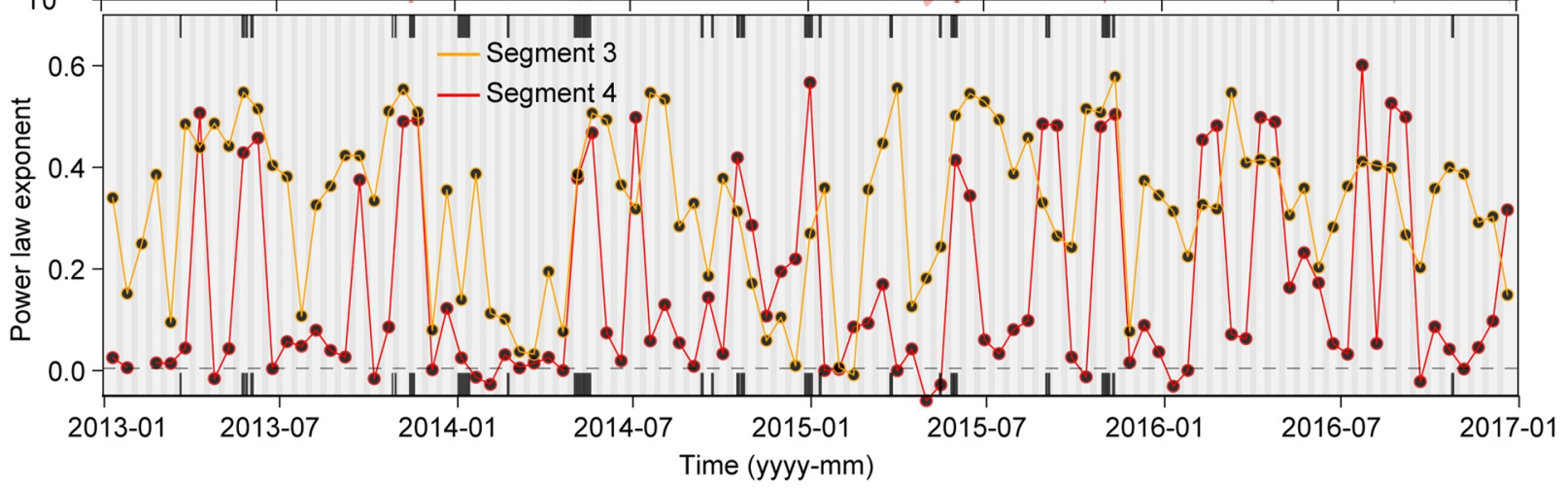

Figure 7. (a) Recurrence intervals of the along-strike segment $S_{3}$, defined as elapsed time between sequential events. Yellow transparent line indicate temporal variation of the power law exponent $\beta$ for segment $S_{3}$. Black vertical bars on the upper and lower edges of the plots indicate timing of short-term SSEs, according to Advanced Industrial Science and Technology-slow slip events (AIST-SSE) catalog (Itaba \& Ando, 2011; Itaba et al., 2013, 2014, 2015; Ochi et al., 2016), occurring in western Shikoku. (b) Recurrence intervals of the along-strike segment $S_{4}$. Red transparent line indicate temporal variation of the power law exponent $\beta$ for segment $S_{4}$ (c) Temporal variation of the power law exponent $\beta$ for segments $S_{3}$ and $S_{4}$ shown by orange and red lines respectively. The estimates for each region are performed in 20-day running window with a 5-day overlap (gray shaded rectangles in background). Black vertical bars on the upper and lower edges of the plots indicate timing of short-term SSEs, according to AIST-SSE catalog (Itaba \& Ando, 2011; Itaba et al., 2013, 2014, 2015; Ochi et al., 2016), occurring in western Shikoku. Light-gray rectangle points the occurrence of Mw 6.2 long-term SSE in the Bungo channel (Ozawa, 2017).

\section{Results}

\subsection{Automatic LFE Catalog for Western and Central Shikoku}

Our final automatic LFE catalog contains in total over 174,000 events detected and located over the analyzed 4-year time period. Space distribution of the events is shown in Figure 1b, illustrating that LFE locations have a highly heterogeneous distribution along the subduction interface with a number of event clusters of different sizes. The most clearly observed feature is the lateral variation of the LFE distribution along the strike direction of subducting PHS plate (Figure $1 \mathrm{~b}$ ) around the depth profile of $30-35 \mathrm{~km}$. This along-strike segmentation is supported by existing studies highlighting the clustered distribution of tectonic tremor and LFE activity along the strike of a belt-like zone at the deeper part of the seismogenic zone in Nankai (e.g., Ide, 2010; Kano et al., 2018; Obara, 2010; Shelly et al., 2006). Such variability is generally considered to be attributed to the lateral variation of physical properties along the plate interphase (Ide, 2010; Kano et al., 2018; Obara et al., 2010). A comparison between our automatic LFE catalog with the tectonic tremor catalog of NIED (Maeda \& Obara, 2009; Obara et al., 2010) and the JMA catalog of manually revised LFEs (Katsumata $\&$ Kamaya, 2003) is provided in supplement Figures S1.1 and S1.2 in Supporting Information S1. It supports the similarity of the global space and time distribution features observed from the automatic catalog and the catalogs produced by different analysis schemes. At the same time, the comparison emphasizes that the 
LFE catalog derived here provides a more detailed view of the activity during the analyzed 4 years, due to a significantly larger number of detected and located LFEs that are not related to the previously identified (template) events. This is seen from the 1-D event-count functions shown in supplement Figure S1.2e in Supporting Information S1, emphasizing that besides the generally increased number of events, our catalog clearly detects significantly more LFEs during the major sequences when the JMA procedure most likely can only extract a limited number of events with the clearest phase arrivals.

Owing to the observed predominant along-strike extension of the LFE activity distribution we will further focus on analyzing in greater detail its characteristics along the strike direction defined as $\mathrm{N} 40^{\circ} \mathrm{E}$. We will use the transformed catalog representation (Figures 1 and $2 \mathrm{~b}$ ) obtained following the coordinate transformation described in Section 3.2.1 (Equation 2), and represent the along-strike LFE location projection relative to the fixed origin. Space-time representation of the LFEs covering the analyzed time-period along the strike direction is shown in Figure 1c. Together with 2-D space representation in Figures 1 and $2 b$ it allows us to make the first observation of the clear along-strike segmentation of LFE activity in space and time, permitting the identification of two main regions of LFE activity corresponding to the western and eastern parts of the study area. These two regions are separated by a less active gap in the central part, at about 125-145 km along-strike distance, that, with the exception of most significant periods of LFE activity (e.g., Figure 2a), acts as a "barrier." The western part is generally the most active, generating the largest number of LFEs, according to the along-strike LFE global event count curve in Figure 2b. At the same time, LFE activity here is more dispersed according to the LFE hypocenter distributions (Figures 1 and 2b), which may be a combined effect of the reduced station coverage and the local difference in slow earthquake generation conditions leading to more complex and mixed signals during tectonic tremor sequences (e.g., Kano et al., 2018; Obara et al., 2010). The major streaks, extending over the distance of up to $200 \mathrm{~km}$ in some cases (Figures 1c and 2a), correspond to intense sequences of LFEs (Figure 2a) migrating along the strike (Figure 2a) and, in most cases, coinciding with geodetically observed short-term SSEs (Hirose \& Obara, 2010, 2020; Sekine et al., 2010). With a couple of exceptions in 2016, all major LFE sequences correspond to, reported by the Geological Survey of Japan, National Institute of Advanced Industrial Science and Technology (AIST), short-term SSEs with equivalent magnitude $\boldsymbol{M}_{\boldsymbol{w}} \sim 6.0$ (Figure 1c). A more detailed comparison between the space-time extent of the short-term SSE fault planes and LFE sequences is provided in supplement Figure S1.2 in Supporting Information S1. A longer-lasting increase of LFE activity in May-October 2014 (Figures 1c and 2a), composed of an intense bilaterally migrating sequence followed by an overall activity increase and intermittently occurring bursts of LFEs in the western part of the region, toward Bungo channel (Figure 2 and Figure S2 in Supporting Information S1), coincide with geodetically detected, long-term SSE of $M_{w} \sim 6.2$ in Bungo Channel (Ozawa, 2017). The feature is most clearly seen in the change of slope of LFE cumulative event numbers for the western part of Shikoku in May 2014 shown in Figure S2b in Supporting Information S1. This influence of long-term SSE occurrence in Bungo channel, representing neighboring slip phenomena (Hirose \& Obara, 2005), on the tremor and LFE activity is well documented by a number of studies (e.g., Kato \& Nakagawa, 2020; Obara et al., 2010). The following sections explore in more detail the overall characteristics of LFE activity during the analyzed 4-year time period focusing on along-strike segmentation, event clustering, and interaction as well as migration properties during the significant LFE sequences.

\subsection{Segmentation of LFE Activity Along the Strike of Subducting Slab}

In this section, we examine in detail the LFE activity pattern correlation and its general statistical characteristics with the scope of defining the along-strike segments with similar LFE behavior.

The results of along-strike LFE event count functions correlation analysis, that follows the procedure described in Section 3.2.2 (Equations 5-7) and assumes the space-time bin sizes [ $\delta t, \delta x]$ of ( 1 day, $2 \mathrm{~km}$ ) for 2-D event count calculations (Figure 2), are summarized in Figure 3. The applied along-strike estimation of binto-bin correlation coefficients (Figure 3a) and the calculated statistic characteristics of along-strike event count functions (Figures $3 \mathrm{~b}$ and $3 \mathrm{c}$ ) allow separating and constraining the distinct along-strike segments of LFEs that are characterized by similar activity patterns over a 4-year time interval. To quantify the similarity level of LFE event count functions and, thus, the degree of potential interaction between the along-strike bins of LFE sources over the analyzed 4-year (e.g., Frank et al., 2016; Trugman et al., 2015), we make use 
of along-strike correlation matrix shown in Figure 3a. Along with the global along-strike LFE event count functions and the 2-D space event count representation (Figure 3c), it highlights the presence of the activity clusters corresponding to the spatially correlated patches of LFEs along the strike. Those are more clear (has larger correlation coefficients) and larger in size toward the central region of the analyzed area, with the dimensions that vary between 10 to $75 \mathrm{~km}$. The most western part is generally characterized by a lower correlation of activity. The patches observable on the correlation matrix (Figure 3a) are in good agreement with the along-strike segments of high LFE event count and are corresponding to the clusters with high LFE event counts in space (Figure 3b).

Next, we combine the above observations with the estimates of standard deviation and the 4th central moment statistical metrics described in Equation 7 and providing information about the along-strike LFE occurrence pattern variation (Shelly \& Johnson, 2011; Trugman et al., 2015). The comparison of the two quantities calculated for the along-strike 4-year long LFE event count functions (Figure 3) indicates that the correlated activity patches identified on the correlation matrix correspond to distinct, well-evidenced, values of standard deviation and 4th moment. This reinforces the finding that LFE sources in western and central Shikoku form distinct, spatially coherent segments with quantitatively similar occurrence patterns.

Gathering together the information provided by different quantities in Figures $3 a-3 c$ we defined seven along-strike segments $S_{1}-S_{7}$ (Figures 2a and 3b) corresponding to the distinct LFE source clusters. More specifically, segment limits are defined at the local minima, separating along-strike picks on the curves of global event count functions (Figure 3b), statistical activity functions (Figure 3c), and corresponding regions of high values on the correlation coefficient matrix (Figure 3a). These segments are most likely to be related to the localized variation of the subducting slab interface properties corresponding to the static (i.e., structural) or dynamic (including fluid transients and local stress history related) heterogeneity. Comparison with the previous studies analyzing triggered tremor activity in western and central Shikoku (Chao \& Obara, 2016; Chao et al., 2013; Kurihara et al., 2018; Miyazawa et al., 2008) indicate that along-strike segments $S_{3}, S_{4}, S_{6}$ and $S_{7}$ also correspond to the previously identified spots of tectonic tremor triggered by teleseismic earthquakes' surface waves, (Figure 1b) implying a fluid-rich environment and the presence of fluid transients. Of the above, segment $S_{3}$ is the most active, generating the largest number of events and, at the same time, corresponding to the largest LFE density over the analyzed time period (Figures $2 b$ and $3 b$ ). However, the energy released at this segment by associated tremor activity is not high, according to the study of Kano et al. (2018). This points toward a very distinct local structural conditions on the subducting plate around segment $S_{3}$ that contributes to the observed high productivity of LFE generation and can be potentially related to the movement of the fluid.

It is worth pointing out that the concept behind the segmentation proposed here is slightly different from that of Obara (2010) or Kano et al. (2018) which are based on the analysis of tremor activity pattern and quantification of the radiated tremor energy during the ongoing SSEs and, thus, based mainly on the response of the tremor or LFE sources to the external forcing during short-term SSEs. The main difference of segmentation proposed here with those from the above studies is that we take into account characteristics of the LFE activity patterns that are reflecting both specific small-scale physical properties (heterogeneity) of the segments along the plate interface and their response to the external forcing. It should be noted that, for example, segments of Obara (2010) generally unite several segments proposed here. Thus, we are attempting to provide a more refined-scale characterization of along-strike LFE activity.

\subsection{Migration Patterns During Periods of Intense LFE Activity}

Estimations of LFE activity front migration speeds focused on selected 12 major LFE sequences extending in time for 7-10 days and covering a minimum of two along-strike segments defined in previous sections (Figure 2a). Comparison with the existing catalogs of the geodetically observed short-term SSEs (Hirose \& Kimura, 2020; Hirose \& Obara, 2010; Sekine et al., 2010) indicates that most of these major sequences are happening during short-term SSEs (Figure 2a and Figure S1.2 in Supporting Information S1). Only 3 of extracted sequences do not correspond to the cataloged short-term SSEs; two of which, in April and October 2016, occur immediately after significant earthquakes (2016 Kumamoto, M 7.3 and 2016 Tottori, M 6.5) located at regional distances $(\sim 200 \mathrm{~km})$ from the studied area of Shikoku. The third one, in September 2016, extending over a large along-strike distance of $\sim 150 \mathrm{~km}$ and migrating from the eastern edge of the 
analyzed region toward the west, is significantly different from episodes featured in the catalog and represents a relatively rare type of sequence observed in the region (e.g., Kano et al., 2018; Obara, 2010; Obara et al., 2011). However, during each of the defined major LFE episodes, a clear along-strike migration of LFE activity is observed.

The approach for estimating the LFE activity front propagation speed described in Section 3.2.3 and assuming a linear relationship between the distance and elapsed time (Equation 8) is illustrated on the example of two selected (representative) LFE sequences with unilateral (Figure 4a) and bilateral (Figure 4b) along-strike front propagation. Summary results for all sequences are shown in Figure 5. Based on the LFE activity space and time evolution during sequences, the migration patterns can be classified in three main categories: (a) eastward migration along strike with the speeds of $\sim 10-40 \mathrm{~km} /$ day in about half of the sequences (number 3, 7, 8, 10 and 12); (b) clear bilateral eastward and westward migration with equal speeds of 6-10 km/day during three sequences (number 2, 4, and 9); (c) westward propagation (three sequences: $1,5,6$ and 11) with the speed of $\sim 6-10 \mathrm{~km} /$ day. Our results for both LFE activity front migration speeds and propagation direction are well in agreement with the observations from previous studies analyzing tremor and LFE activity episodes during the SSEs in Shikoku (e.g., Ide, 2010; Kano et al., 2018; Obara, 2002, 2010; Shelly et al., 2007b). We observe that all eastward propagation sequences start in the western part of the analyzed region extending toward its center or further to the east. Westward propagation sequences are mainly starting at the most eastern edge of the region extending to the central part. The initiation points of bilaterally propagation sequences 2 and 4 are located at about $70 \mathrm{~km}$ along-strike distance and $100 \mathrm{~km}$ for sequence 9. The only anomalous, from the point of view of extension and front propagation speed, is a sequence from September 2016 (number 11), that is estimated to propagate at a low speed ( 4.0 km/day) in westward direction with no short- or long-term SSE associated, according to the available catalogs. We cannot explain which phenomenon could be behind the initiation and propagation of this sequence. At the same time, following the lines of our analysis, LFE sequences occurring immediately after the major $(\mathrm{M}>$ 6.5) earthquakes in April and October 2016, are similar (in terms of propagation speed and direction) to the other sequences associated to ongoing SSE. Thus, also given the fact that those sequences are active in the western part of the Shikoku region with the most active short-term SSEs (e.g., Hirose \& Obara, 2010) (Figure S1.2 in Supporting Information S1), it is highly likely that they are as well accompanied by the short-term SSEs that went undetected, most probably, due to the intense aftershock activity and contamination by the post-seismic phase.

A number of previous studies analyzing tectonic tremors (Ando et al., 2012; Ide, 2010; Kano et al., 2018), as well as LFE activity (Kato \& Nakagawa, 2020), pointed out diffusive patterns of the propagation front. Visual inspection of the LFE sequences in our automated catalog also indicates that for some of the analyzed sequences migration front may correspond to diffusive shape (Figures 4a and 4b, Figure S3.2 in Supporting Information S1). Following the analysis scheme presented in Section 3.2.3 and assuming diffusive pattern of LFE front propagation described by Equation 9 for sequences in Figure 4, we obtain the diffusion coefficients of $\sim 10^{3}-\sim 10^{4} \mathrm{~m}^{2} / \mathrm{s}$. These estimates are within the range of values reported by previous studies using tectonic tremor signals (Ando et al., 2012; Ide, 2010; Kano et al., 2018) and LFE observations (Kato \& Nakagawa, 2020). Stress diffusion model with fluid lubrication has been considered as a possible mechanism of tremor episodes accompanying the slow slip by a number of studies (Ando et al., 2012; Ide, 2008; Kano et al., 2018). However, our analysis does not provide strong support that the LFE migration front is always clearly diffusive, as it can be, generally, equally well approximated by a linear front propagation model (Figure 4, Figure S3.2 in Supporting Information S1).

\subsection{LFE Activity Time-Clustering and Interaction}

Here we present the results of time clustering analysis explained in Section 3.2.4 (Equation 11) and aiming at quantifying the clustering and interaction of LFE activity corresponding to the defined (Section 4.3) along-strike segments. The analysis also allows to assess how strong is the LFE clustering during the periods corresponding to the cataloged long- or short-term SSEs (Frank, 2016; Frank, Rousset, et al., 2018; Idehara et al., 2014) and understand its characteristics in the periods between those for different along-strike segments. 
The analysis is initially carried on the example of two along-strike segments: $S_{3}$ and $S_{4}$ having clearly distinct types of LFE activity patterns observable on both temporal along-strike distribution of LFEs (Figure 1c), as well as cumulative event count plots shown in Figures 6a and 6d. Segment $S_{3}$ is characterized by a more continuous activity visible as horizontal streaks on Figures $1 \mathrm{c}$ and 2a pointing that it is active not only during the major LFE sequences but in-between them as well (Figure 6a). At the same time, segment $S_{4}$ has a clearly episodic LFE activity pattern with short burst-like periods separated by periods of very low activity (Figure 2a) with a nearly constant rate of event occurrence (Figure 6d). We first select two time periods corresponding to the 145 days-long interval between the major LFE sequences and following it, 40 dayslong, LFE sequence (coinciding with a short-term SSE) for both $S_{3}$ (Figure 6a) and $S_{4}$ (Figure 6d) segments. For each of those, we estimate the event count function (Equation 10) with a regular time-step of $20 \mathrm{~s}$ and then compute the auto-correlation function of these time series, following Equation 11 (Figures $6 \mathrm{~b}$ and $6 \mathrm{e}$ ). The degree of clustering is then assessed by estimating the power law exponent $\beta$ of the auto-correlation Fourier spectrum (Equation 11). Values of exponent close to zero indicate a Poisson-like event occurrence (Dirac auto-correlation function), while values significantly larger than zero correspond to a strongly clustered process. Our analysis of the selected time-windows for the two segments $S_{3}$ and $S_{4}$ shows that a Diraclike auto-correlation at zero lag, corresponding to the flat spectrum (at short spectral periods of $10^{-3}-10^{-1}$ days), is observed only for the inter-sequence time-window of segment $S_{4}$ (black line in Figures 6e and 6f). For segment $S_{3}$, LFEs occurring in both co-sequence and inter-sequence time-periods, exhibit some degree of time clustering corresponding to clearly non-zero $\beta$ (Figure $6 \mathrm{c}$ ). The degree of clustering during the time window of the major LFE sequence for segment $S_{3}$ is close to that of segment $S_{4}$ (Figures $6 \mathrm{c}$ and $6 \mathrm{f}$ ) and is significantly larger than inter-sequence spectral slope. This implies that although strongest event clustering is observed through the major LFE sequences (corresponding to SSEs), during which both along-strike segments are active, LFEs of segment $S_{3}$ exhibit time-clustering in the inter-sequence periods as well.

We further extend the analysis to the full 4-year time period, measuring the spectral slope $\beta$ for along-strike segments $S_{3}$ and $S_{4}$ in 20-day running window with a 5-day overlap. Figure 7, summarizing the results, indicates that a clear increase of spectral slope $\beta$ is associated with every major sequence of LFE activity that is coincident for both along-strike segments and, generally, corresponds to the cataloged short-term SSEs (Figure 7). This implies that the strongest clustering and interaction between the LFEs are observed during the SSEs, or strong sequences (with no detected slow-slip component) that typically extend over the large $(>50 \mathrm{~km})$ along-strike distances. At the same time, during the inter-sequence, or inter-SSE periods, low values of power law exponent $\beta$ for segment $S_{4}$ indicate independent LFE occurrence with no time clustering (Figure $7 \mathrm{~b}$ ), while for segment $S_{3}$ power law exponent is often higher than background values (Figure 7c). Those values for segment $S_{3}$ are generally well correlated to the minor bursts of LFEs observable on the inter-event time plot (Figure 7a). The observed difference in the temporal pattern of LFE occurrence between the two along-strike segments likely implies that the activity of segment $S_{3}$ is either influenced by very local-scale processes in place (two segments are located close to each other), or there is a significant, strongly-localized, difference in the along-strike subducting slab properties, such as velocity anomaly (e.g., Ide, 2010; Idehara et al., 2014) related, for example, to the differences in the geochemical composition of the material and/or presence of trapped fluids corresponding to the two segments. In the following section (Section 5) we discuss in more detail the potential relation between the LFE activity segmentation and subduction zone properties.

The clustering analysis scheme can be further extended to the other along-strike segments. However, our results (Figure S4 in Supporting Information S1) indicate that for some of the segments (other than $S_{3}$ and $S_{4}$ ) it is difficult to obtain a clear separation between the periods of time exhibiting strongly clustered behavior of events from fully non clustered, independent, LFE activity. This can be, on one hand, an indication that LFE activity in the analyzed Shikoku region and its connection to slow slip component, as well as structural properties along the subducting slab, are highly complex. On the other hand, it may as well point toward the fact that the time resolution of our catalog is not sufficient (compared to the template-based catalog used by e.g., Frank et al., 2016) to capture the signature of LFE activity pattern required for statistical characterization of those segments, or a different approach to quantitative clustering and interaction analysis should be adopted. Investigating these aspects in further detail is out of the scope of this study. 


\section{Discussion: LFE Activity Patterns and Relation to Subduction Zone Complexity}

Temporal patterns of tremor or LFE occurrence are generally characterized as episodic with the short-period burst-like activity separated by periods of inactivity (e.g., Obara et al., 2010, 2011). The spatial variation of the tremor or LFE activity through a tectonic region was mostly analyzed in greater detail in the context of depth-dependent occurrence modes in southwest Japan (Obara et al., 2010, 2011), Cascadia (Wech \& Creager, 2011) and Guerrero (Frank et al., 2016) subduction zones, as well as along San Andreas (California) and Alpine (New Zealand) Faults (Chamberlain et al., 2014; Shelly, 2015; Shelly \& Johnson, 2011; Trugman et al., 2015). Such depth-dependent spatial heterogeneity is considered to reflect the variation of the frictional regime (e.g., Obara et al., 2010, 2011) due to the thermal condition, serpentinization, and/or high fluid pore-pressure. Although in this study we only focus on the along-strike LFE activity, neglecting the depth-dependent information, owing to the fact that tectonic tremor at the shallower part of the tremor zone is reported to be more active (e.g., Obara et al., 2010, 2011), our along-strike characterization is most likely to be dominated by those shallower sources.

Along-strike heterogeneity in tremor or LFE activity in southwestern Japan was mainly analyzed in the context of short- and long-term SSE occurrence (Hirose \& Kimura, 2020; Kano et al., 2018; Obara, 2010), variation in energy release during intense periods of tremor activity (Kano et al., 2018; Yabe \& Ide, 2014) or very low-frequency earthquakes occurrence rate (Baba et al., 2020). The proposed segmentation (Kano et al., 2018; Obara et al., 2010) separating the western most part of Shikoku, roughly corresponding to alongstrike distances of $\sim 0-90 \mathrm{~km}$ (Figure 1c), central Shikoku region at $\sim 90-150 \mathrm{~km}$ along strike (Figure 1c) and eastern Shikoku $\sim 150-225 \mathrm{~km}$ along strike (Figure 1c) was demonstrated to correspond to a significant difference in radiated tremor energy and short-term SSE occurrence (e.g., Kano et al., 2018). Western Shikoku is known to have the highest ratio of deep low-frequency tremor energy release along the Nankai through (Annoura et al., 2016) and most of the short-term SSEs are observed here (Kano et al., 2018; Obara et al., 2010) (Figure S1.2 in Supporting Information S1). These along-strike differences are attributed to the lateral variation in the strength of tremor patches linked to the along-strike differences of Vp/Vs ratio in the overriding plate and observed between western and central Shikoku (e.g., Kita \& Matsubara, 2016; Nakajima \& Hasegawa, 2016). Similarly to the observations from other subduction regions (e.g., Audet \& Schwartz, 2013) relatively high $V_{P} / V_{S}$ ratio of the overriding plate associated to the detectable SSEs, as observed in western Shikoku, is explained by the leakage of fluids into the overriding plate resulting in decreased fluid pressure and higher strength patches (e.g., Kano et al., 2018). Tremor patches that can be easily ruptured by external stress perturbations caused by the tide or distant large earthquakes (e.g., Ide, 2010; Miyazawa et al., 2008), such as those of central and eastern Shikoku, are mostly related to regions rich in fluids.

In contrast to the above studies, our analysis provides an along-strike segmentation of LFE activity that is based on the statistical analysis of the LFE occurrence patterns and their similarity (through correlation analysis) during the overall analyzed period of 4 years and is not necessarily related to the occurrence of SSEs. On the large scale, space and time distribution of LFEs and their activity patterns, as well as the extracted here along-strike segments, respect the distinction between western Shikoku (composed of segments $S_{1}-S_{3}$; Figures 2a and 3) and eastern Shikoku (segments $S_{6}$ and $S_{7}$ ), separated by a central region (segments $S_{4}$ and $S_{5}$ ) suggested by previous studies (Hirose \& Kimura, 2020; Idehara et al., 2014; Kano et al., 2018; Obara, 2010). However, since our segmentation is not necessarily related to SSEs, that typically extend over the multiple along-strike regions (Figure 2a), it provides a more detailed characterization of along-strike LFE activity variation. It can be noticed that segments $S_{1}$ and $S_{2}$, with an extent of $\sim 80 \mathrm{~km}$ along strike are significantly different from other segments in terms of LFE activity features imaged by correlation matrix and along-strike event count functions (Figures 3a-3c), supporting the distinct slow earthquakes generation environment suggested by previous studies. Segments $S_{3}-S_{7}$, on the other hand, are described by particular statistical characteristics of temporal LFE activity and well-defined high correlation of temporal event count functions over the analyzed 4-year period. We suggest that these segments corresponding to the LFE activity clusters may represent individual regions related to the localized variation of properties corresponding to the static (i.e., structural) or dynamic (including fluid transients and local stress history related) heterogeneities along the subducting slab interface. The coincidence of segments $S_{3}, S_{4}, S_{6}$, and $S_{7}$ with the previously reported spots of tectonic tremor triggered by teleseismic earthquakes' surface waves 
(Figure 1b; Chao \& Obara, 2016; Chao et al., 2013; Kurihara et al., 2018; Miyazawa et al., 2008) supports a fluid-rich environment and fluid transients. It can be noticed that segment $S_{5}$, having a strongly episodic activity pattern and being activated only during the major (strongest) sequences, behaves more like a barrier that may potentially correspond to a subducting seamount (Ide, 2010, 2012).

The large-scale LFE activity segmentation, observed from our automatic LFE catalog, divides the study region into the western and eastern zones separated by a gap or barrier that is "broken" during some of the major sequences associated with SSE occurrence (Figure 1 and Figure S1 in Supporting Information S1). It reflects the structural complexity of the subducting environment (subduction interface and the oceanic crust) corresponding to the static heterogeneity, and the difference in the tectonic evolution overlapped with the potential memory-dependent stress variation or fluid circulation (dynamic heterogeneity), for the corresponding regions of Shikoku. As mentioned before, such segmentation is observed as well by other studies analyzing various slow earthquakes phenomena and is attributed to the along-strike variation of $\mathrm{Vp} /$ Vs ratio in the overriding plate and observed between western and central Shikoku (e.g., Kita \& Matsubara, 2016; Nakajima \& Hasegawa, 2016). This also implies that material in the vicinity of the subduction interface in the eastern part is mechanically weaker. One important aspect influencing this variation should be related to the observed along-strike west to east change of the subducting PHS slab age and, implicitly, temperature from older and colder in the west to younger and warmer in the east (Hua et al., 2018). This variation in the temperature affects slab dehydration reactions which are related to the fluid content of the overriding plate observed by tomographic studies (e.g., Nakajima \& Hasegawa, 2016). Another important issue that may provide the explanation of the observed segmentation is related to the along-strike variation of the subducting slab topography and the existence of the Kinan seamount chain in the east, in front of Cape Muroto (Figure 1a). Existence of the subducting seamount located southeast of the cape was confirmed by some of the studies (e.g., Okamura \& Shishikura, 2020), implying also the possibility that a similar feature could be found at the greater depth influencing local slab geometry at the depth of deep tectonic tremor occurrence. It is also important to stress that there exists as well strong evidence for the difference in the collisions tectonic regimes between the western and eastern Shikoku that was implied in support of the observed segmentation of Shimanto accretionary complex derived from the difference in geological and geophysical properties at capes Ashizuro and Muroto (Kimura et al., 2014; Figure 1). This accretionary complex distributed along the Pacific side of southwest Japan is believed to represent an ancient on-land analog of the Nankai Trough subduction zone (Ujiie \& Kimura, 2014). The subduction melange of the Shimanto complex was identified by Ujiie et al. (2018) as the structure in which tectonic tremors occur. Thus, spatial variation of tremor and LFE activity could reflect the heterogeneity and variation of melange's physical properties, and there potentially exists a complex overlap of different factors acting together and conditioning the along-strike segmentation of LFE activity on multiple scales evidenced in our study.

One of the important results derived from the analysis of the fully automated LFE catalog presented here is provided by the quantitative characterization of LFE time-clustering variation in time. This part of the LFE catalog analysis follows the approach of Frank et al. (2016), that first used point process formalism to analyze the evolution of LFE interaction in Guerrero, Mexico. Similarly to their results, we show that LFEs are active all the time, not only during the periods of major tremor sequences or SSEs. Furthermore, we show that while LFEs exhibit strongly collective behavior during the major tremor sequences over the multiple activated segments (that may or may not correspond to the cataloged short- or long-term SSEs; Figure 2a and Figure S1.2 in Supporting Information S1), event time-clustering during inter-sequence periods can vary significantly among different along-strike segments. On the example of segments $S_{3}$ and $S_{4}$ characterized, respectively, by semi-continuous and episodic LFE activity patterns, we show that LFEs can act independent from one another with close to Poisson-like event occurrence during inter-sequence periods (segment $S_{4}$, Figure 7b). At the same time, a variable degree of interaction can as well exist (segment $S_{3}$, Figure 7a). This distinction between the LFE interaction during and between the major sequences is even more complex for other regions $\left(S_{1}, S_{2}\right.$ and $S_{5}-S_{7}$; Figure S4 in Supporting Information S1). Although our observation of strong interaction between the LFEs during the SSEs or tremor sequences coincides with the results of Frank et al. (2016), we do not observe that clear separation between strongly interacting and Poisson-like LFE event occurrence for all the along-strike segments defined in the present study. This can be due to the significantly larger along-strike extent and a more complex segmentation of the tremor and LFE activity in the Shikoku region analyzed here, in comparison to the predominant down-dip segmentation in 
Guerrero (Frank et al., 2016). Most of the SSE events in Shikoku are occurring in its western part, having small or no effect on the tremor or LFE activity toward the east (Figures S1.1 and S1.2 in Supporting Information S1). At the same time, the observed complexity of LFE activity segmentation and interaction in Shikoku can also be attributed to a more complex variation of physical properties and geometry of the subduction zone as well as its tectonic history. Thus, observed here differences in temporal pattern of LFE time-clustering support the along-strike segmentation of LFE activity in western and central Shikoku and imply that, in some cases, such as segments $S_{3}$ and $S_{4}$, there may exist very local-scale process or significant difference in the along-strike subducting slab properties, such as strongly-localized velocity anomalies (e.g., Ide, 2010; Idehara et al., 2014) or fluid circulation channels. Similar to Frank et al. (2016) we point out that analysis of LFE activity behavior should provide information about the state of the fault contact along the subducting plate interface in time.

The migration patterns, such as front migration speed and directions, estimated from the analysis of major LFE sequences appearing in our catalog are in good general agreement with the results of previous studies for the Shikoku region (Ide, 2010; Obara et al., 2010, 2011). We also confirm the observations that some of the sequences exhibit potential diffusive patterns with estimated diffusion coefficients of $\sim 10^{3}-\sim 10^{4} \mathrm{~m}^{2} / \mathrm{s}$ (Figure S3.2 in Supporting Information S1), which is similar to the results reported by Ide (2010) and following more recent studies of Kano et al. (2018) and Kato and Nakagawa (2020). However, we could not confirm the multi-scale diffusion pattern observed during the major LFE sequences by Kato and Nakagawa (2020). This, we consider, could be mainly attributed to the lower temporal resolution of our automatic LFE catalog, which is limited to the $20 \mathrm{~s}$ size of the sliding window assumed in the detection and location scheme, in comparison to the templated-based LFE catalogs (e.g., Frank \& Shapiro, 2014; Frank et al., 2013; Kato \& Nakagawa, 2020).

Our study provides strong support that detailed analysis of LFE activity in space and time can offer an alternative, indirect, way to monitor the temporal variations of physical properties in relation to slow earthquakes that may further help to understand fluid-driven processes and their effect on slip behavior along the plate interface (Gosselin et al., 2020; Nakajima \& Uchida, 2018). The existence of highly resolved in space and time LFE catalogs is thus of crucial importance. We stress that the setup of our detection and location scheme is specifically tuned to the specific characteristics of LFE signals and focused on the region where tremor and LFE activity are predominant. At the same time, the catalog can still be contaminated by local or regional earthquakes. The comparison with the NIED tectonic tremor and JMA LFE catalogs (Figures S1.1 and S1.2 in Supporting Information S1), as well as the observation of tremor and LFE activity along-strike segmentation (Kano et al., 2018; Kato \& Nakagawa, 2020; Obara et al., 2010), points out that this contamination would not affect the overall (large-scale) LFE activity characteristics discussed in the current study. However, this issue will be addressed in the following analysis aiming at combining the fully automatic catalog presented here, LFE targeted signal characterization, and the observation from the LFE source study analysis (Supino et al., 2020) for characterizing the automatic detection and performing LFE template extraction.

\section{Conclusions}

We derived an extensive automatic catalog of over 174,000 LFEs in western and central Shikoku by applying a coherency-based method BackTrackBB (Poiata et al., 2016, 2018) to the continuous seismic data covering the 4-year period (January 2013-December 2016) and recorded by the Hi-net station of NIED. Our catalog represents the first LFE catalog obtained using the method that does not rely on a priory template events available for the region of interest and provides a result of a homogeneous processing scheme. It allows to analyze and characterize the main LFE activity features over the selected 4-year period, illustrating that LFE activity in the targeted region of Shikoku is highly heterogeneous in space and time. We observe a space distribution with clear heterogeneity in along-strike direction of the subducting Philippine sea plate composed of a number of different size segments. Some of those segments are being highly productive in LFE generation. This along-strike segmentation is supported by previous studies (e.g., Hirose \& Kimura, 2020; Idehara et al., 2014; Kano et al., 2018; Obara, 2010) and is attributed to the lateral variation of the physical properties along the plate interfaces. A more detailed analysis making use of statistical characteristics and correlation coefficients of along-strike 4-year long LFE event count functions, allows us to define and ex- 
tract individual 7 along-strike regions (segments) corresponding to different LFE occurrence patterns. We suggest that these segments are related to the distinct, localized variation in the properties of the subduction slab interface, that may correspond to the localized static (such as structural) or dynamic (corresponding to memory-dependent stress variations or possible fluid transients) heterogeneities, and confirm that regions with highest LFE productivity correspond to the previously identified spots of tectonic tremor triggered by teleseismic earthquakes' surface waves supporting a fluid-rich environment and potential fluid transients.

We observe that the largest complexity of LFE activity corresponds to the major LFE sequences, accompanying the geodetically observed short-term SSEs. These major LFE sequences are typically extending over multiple defined along-strike regions and have a slowly migrating front with the speed of $\sim 8-35 \mathrm{~km} /$ day, confirming the previous observation in the Nankai and Cascadia subduction zones. Some of the LFE sequences show diffusion-like migration patterns. Time-clustering analysis indicates that there exist strong LFE interactions during tremor bursts and major tremor sequences associated with the short-term SSEs. However, during inter-tremor or inter-SSE time-periods the degree of LFE interaction varies significantly along-strike, from independent to strongly clustered in time. This variation in the characteristics of LFE activity, also, likely reflects localized along-strike changes in subducting-slab properties.

Our analysis points out that detailed catalogs of LFEs produced by the homogeneous automatic schemes, such as BackTrackBB presented here, and allowing for a detailed statistical analysis of the space-time variability of LFE activity clustering and migration patterns, should contribute to the quantification of the potential time-variable processes associated with slow earthquake activity and fluid transients. Moreover, a (near) real-time data streaming application of the BackTrackBB detection and location method combined with the catalog analysis scheme presented here, may provide new monitoring opportunities for the slow earthquake processes at different scales (LFEs to slow slip events) contributing to more detailed information about the locking state along the Nankai subduction zone.

\section{Data Availability Statement}

The seismological time series used for this analysis are available from the National Institute for Earth Science and Disaster Prevention (http://www.hinet.bosai.go.jp). The software used for detection and location is available from Git-Hub (http://backtrackbb.github.io). The low-frequency earthquake catalog of Japan Meteorological Agency (JMA), the NIED-tremor, and AIST short-term SSE catalogs used for comparison in this paper can be downloaded from Slow Earthquake Database (http://www-solid.eps.s.u-tokyo.ac. jp/ sloweq/). Full automatic LFE catalog is available from https://doi.org/10.31905/UOQ9LVHZ. Part of data analysis has been performed using ObsPy (Krischer et al., 2015). Figures have been produced using the Generic Mapping Tools (Wessel et al., 2019) and Matplotlib (Hunter, 2007).

\section{Acknowledgments}

This study was supported by the European Research Council under the European Union Horizon 2020 research and innovation program (grant agreement no. 787399-SEISMAZE). The research also benefited from the support of JSPS KAKENHI Grant Number JP16H06473 in Scientific Research on Innovative Areas "Science of Slow Earthquakes" from Japanise side. The authors express their thanks to the editor M. Bostock, A. Plourde, and an anonymous reviewer for their constructive and insightful comments. Most numerical computations were performed on the S-CAPAD platform, at Institut de Physique du Globe de Paris (IPGP), France. We thank Geneviève Moguilny for the help with computational and data storage resources.

\section{References}

Ando, R., Takeda, N., \& Yamashita, T. (2012). Propagation dynamics of seismic and aseismic slip governed by fault heterogeneity and Newtonian rheology. Journal of Geophysical Research: Solid Earth, 117(B11). https://doi.org/10.1029/2012jb009532

Annoura, S., Obara, K., \& Maeda, T. (2016). Total energy of deep low-frequency tremor in the Nankai subduction zone, southwest Japan. Geophysical Research Letters, 43(6), 2562-2567. https://doi.org/10.1002/2016gl067780

Audet, P., Bostock, M. G., Christensen, N. I., \& Peacock, S. M. (2009). Seismic evidence for overpressured subducted oceanic crust and megathrust fault sealing. Nature, 457(7225), 76-78. https://doi.org/10.1038/nature07650

Audet, P., \& Bürgmann, R. (2014). Possible control of subduction zone slow-earthquake periodicity by silica enrichment. Nature, 510(7505), 389-392. https://doi.org/10.1038/nature13391

Audet, P., \& Schwartz, S. Y. (2013). Hydrologic control of forearc strength and seismicity in the Costa Rican subduction zone. Nature Geoscience, 6(10), 852-855. https://doi.org/10.1038/ngeo1927

Baba, S., Takemura, S., Obara, K., \& Noda, A. (2020). Slow earthquakes illuminating interplate coupling heterogeneities in subduction zones. Geophysical Research Letters, 47(14), e2020GL088089. https://doi.org/10.1029/2020gl088089

Beaucé, E., Frank, W. B., Paul, A., Campillo, M., \& van der Hilst, R. D. (2019). Systematic detection of clustered seismicity beneath the southwestern Alps. Journal of Geophysical Research: Solid Earth, 124(11), 11531-11548. https://doi.org/10.1029/2019jb018110

Beroza, G. C., \& Ide, S. (2011). Slow earthquakes and nonvolcanic tremor. Annual Review of Earth and Planetary Sciences, 39, $271-296$. https://doi.org/10.1146/annurev-earth-040809-152531

Bostock, M., Royer, A., Hearn, E., \& Peacock, S. (2012). Low frequency earthquakes below southern Vancouver Island. Geochemistry, Geophysics, Geosystems, 13(11). https://doi.org/10.1029/2012gc004391

Brown, J. R., Beroza, G. C., Ide, S., Ohta, K., Shelly, D. R., Schwartz, S. Y., \& Kao, H. (2009). Deep low-frequency earthquakes in tremor localize to the plate interface in multiple subduction zones. Geophysical Research Letters, 36(19). https://doi.org/10.1029/2009gl040027 
Brudzinski, M. R., \& Allen, R. M. (2007). Segmentation in episodic tremor and slip all along Cascadia. Geology, 35(10), 907-910. https:// doi.org/10.1130/g23740a.1

Chamberlain, C. J., Shelly, D. R., Townend, J., \& Stern, T. A. (2014). Low-frequency earthquakes reveal punctuated slow slip on the deep extent of the alpine fault, New Zealand. Geochemistry, Geophysics, Geosystems, 15(7), 2984-2999. https://doi.org/10.1002/2014gc005436

Chao, K., \& Obara, K. (2016). Triggered tectonic tremor in various types of fault systems of Japan following the 2012 Mw8. 6 Sumatra earthquake. Journal of Geophysical Research: Solid Earth, 121(1), 170-187. https://doi.org/10.1002/2015jb012566

Chao, K., Peng, Z., Gonzalez-Huizar, H., Aiken, C., Enescu, B., Kao, H., et al. (2013). A global search for triggered tremor following the 2011 Mw 9.0 Tohoku earthquake. Bulletin of the Seismological Society of America, 103(2B), 1551-1571. https://doi.org/10.1785/0120120171

Frank, W., \& Shapiro, N. (2014). Automatic detection of low-frequency earthquakes (LFES) based on a beamformed network response. Geophysical Journal International, 197(2), 1215-1223. https://doi.org/10.1093/gji/ggu058

Frank, W., Shapiro, N., Husker, A., Kostoglodov, V., Romanenko, A., \& Campillo, M. (2014). Using systematically characterized low-frequency earthquakes as a fault probe in Guerrero. Journal of Geophysical Research: Solid Earth, 119, 7686-7700. https://doi. org/10.1002/2014jb011457

Frank, W. B. (2016). Slow slip hidden in the noise: The intermittence of tectonic release. Geophysical Research Letters, 43(19), 10-125. https://doi.org/10.1002/2016gl069537

Frank, W. B., Rousset, B., Lasserre, C., \& Campillo, M. (2018). Revealing the cluster of slow transients behind a large slow slip event. Science Advances, 4(5). eaat0661. https://doi.org/10.1126/sciadv.aat0661

Frank, W. B., Shapiro, N. M., \& Gusev, A. A. (2018). Progressive reactivation of the volcanic plumbing system beneath Tolbachik volcano (Kamchatka, Russia) revealed by long-period seismicity. Earth and Planetary Science Letters, 493, 47-56. https://doi.org/10.1016/j. epsl.2018.04.018

Frank, W. B., Shapiro, N. M., Husker, A. L., Kostoglodov, V., Bhat, H. S., \& Campillo, M. (2015). Along-fault pore-pressure evolution during a slow-slip event in Guerrero, Mexico. Earth and Planetary Science Letters, 413, 135-143. https://doi.org/10.1016/j.epsl.2014.12.051

Frank, W. B., Shapiro, N. M., Husker, A. L., Kostoglodov, V., Gusev, A. A., \& Campillo, M. (2016). The evolving interaction of low-frequency earthquakes during transient slip. Science Advances, 2(4), e1501616 . https://doi.org/10.1126/sciadv.1501616

Frank, W. B., Shapiro, N. M., Kostoglodov, V., Husker, A. L., Campillo, M., Payero, J. S., \& Prieto, G. A. (2013). Low-frequency earthquakes in the Mexican sweet spot. Geophysical Research Letters, 40(11), 2661-2666. https://doi.org/10.1002/grl.50561

Ghosh, A., Vidale, J. E., Sweet, J. R., Creager, K. C., Wech, A. G., Houston, H., \& Brodsky, E. E. (2010). Rapid, continuous streaking of tremor in Cascadia. Geochemistry, Geophysics, Geosystems, 11(12). https://doi.org/10.1029/2010gc003305

Gosselin, J. M., Audet, P., Estève, C., McLellan, M., Mosher, S. G., \& Schaeffer, A. J. (2020). Seismic evidence for megathrust fault-valve behavior during episodic tremor and slip. Science Advances, 6(4), eaay5174. https://doi.org/10.1126/sciadv.aay5174

Hirose, H., \& Kimura, T. (2020). Slip distributions of short-term slow slip events in Shikoku, southwest Japan, from 2001 to 2019 based on tilt change measurements. Journal of Geophysical Research: Solid Earth, 125(6), e2020JB019601. https://doi.org/10.1029/2020jb019601

Hirose, H., \& Obara, K. (2005). Repeating short-and long-term slow slip events with deep tremor activity around the Bungo channel region, southwest Japan. Earth Planets and Space, 57(10), 961-972. https://doi.org/10.1186/bf03351875

Hirose, H., \& Obara, K. (2010). Recurrence behavior of short-term slow slip and correlated nonvolcanic tremor episodes in western Shikoku, southwest Japan. Journal of Geophysical Research: Solid Earth, 115(B6). https://doi.org/10.1029/2008jb006050

Houston, H., Delbridge, B. G., Wech, A. G., \& Creager, K. C. (2011). Rapid tremor reversals in Cascadia generated by a weakened plate interface. Nature Geoscience, 4(6), 404-409. https://doi.org/10.1038/ngeo1157

Hua, Y., Zhao, D., Xu, Y., \& Liu, X. (2018). Age of the subducting Philippine Sea slab and mechanism of low-frequency earthquakes. Geophysical Research Letters, 45(5), 2303-2310. https://doi.org/10.1002/2017gl076531

Hunter, J. D. (2007). Matplotlib: A 2d graphics environment. Computing in Science \& Engineering, 9(3), 90-95. https://doi.org/10.1109/ mcse. 2007.55

Ide, S. (2008). A brownian walk model for slow earthquakes. Geophysical Research Letters, 35(17). https://doi.org/10.1029/2008gl034821

Ide, S. (2010). Striations, duration, migration and tidal response in deep tremor. Nature, 466(7304), 356-359. https://doi.org/10.1038/ nature09251

Ide, S. (2012). Variety and spatial heterogeneity of tectonic tremor worldwide. Journal of Geophysical Research: Solid Earth, 117(B3). https://doi.org/10.1029/2011jb008840

Ide, S., Shelly, D. R., \& Beroza, G. C. (2007). Mechanism of deep low frequency earthquakes: Further evidence that deep non-volcanic tremor is generated by shear slip on the plate interface. Geophysical Research Letters, 34(3). https://doi.org/10.1029/2006gl028890

Idehara, K., Yabe, S., \& Ide, S. (2014). Regional and global variations in the temporal clustering of tectonic tremor activity. Earth Planets and Space, 66(1), 66. https://doi.org/10.1186/1880-5981-66-66

Imanishi, K., Uchide, T., \& Takeda, N. (2016). Determination of focal mechanisms of nonvolcanic tremor using S wave polarization data corrected for the effects of anisotropy. Geophysical Research Letters, 43(2), 611-619. https://doi.org/10.1002/2015gl067249

Itaba, S., \& Ando, R. (2011). A slow slip event triggered by teleseismic surface waves. Geophysical Research Letters, 38(21). https://doi. org/10.1029/2011gl049593

Itaba, S., Kitagawa, Y., Koizumi, N., Takahashi, M., Matsumoto, N., Takeda, N., et al. (2013). Short-term slow slip events in the Tokai area, the Kii peninsula and the Shikoku district, Japan (from November 2012 to April 2013). Report of the Coordinating Committee for Earthquake Prediction, 90, 254-269.

Itaba, S., Koizumi, N., Takahashi, M., Matsumoto, N., Kitagawa, Y., Ochi, T., et al. (2015). Short-term slow slip events in the Tokai area, the Kii peninsula and the Shikoku District, Japan (from May to October 2014). Report of the Coordinating Committee for Earthquake Prediction, 93, 330-335.

Itaba, S., Koizumi, N., Takahashi, M., Matsumoto, Y. N., Kitagawa, Ochi, T., Takeda, N., et al. (2014). Short-term slow slip events in the Tokai area, the Kii peninsula and the Shikoku district, Japan (from November 2013 to April 2014). Report of the Coordinating Committee for Earthquake Prediction, 92, 238-249.

Kagan, Y. Y., \& Jackson, D. D. (1991). Long-term earthquake clustering. Geophysical Journal International, 104(1), 117-134. https://doi. $\operatorname{org} / 10.1111 / j .1365-246 x .1991 . t b 02498 . x$

Kano, M., \& Kato, A. (2020). Detailed spatial slip distribution for short-term slow slip events along the Nankai subduction zone, southwest Japan. Journal of Geophysical Research: Solid Earth, 125(7). e2020JB019613. https://doi.org/10.1029/2020jb019613

Kano, M., Kato, A., Ando, R., \& Obara, K. (2018). Strength of tremor patches along deep transition zone of a megathrust. Scientific Reports, 8(1), 1-8. https://doi.org/10.1038/s41598-018-22048-8

Kao, H., Shan, S.-J., Dragert, H., Rogers, G., Cassidy, J. F., \& Ramachandran, K. (2005). A wide depth distribution of seismic tremors along the northern cascadia margin. Nature, 436(7052), 841-844. https://doi.org/10.1038/nature03903 
Kato, A., \& Nakagawa, S. (2020). Detection of deep low-frequency earthquakes in the Nankai subduction zone over 11 years using a matched filter technique. Earth Planets and Space, 72(1), 1-9. https://doi.org/10.1186/s40623-020-01257-4

Katsumata, A., \& Kamaya, N. (2003). Low-frequency continuous tremor around the Moho discontinuity away from volcanoes in the southwest Japan. Geophysical Research Letters, 30(1), 20-21. https://doi.org/10.1029/2002gl015981

Kim, Y., Clayton, R., \& Jackson, J. (2010). Geometry and seismic properties of the subducting Cocos plate in central Mexico. Journal of Geophysical Research, 115(B6). https://doi.org/10.1029/2009jb006942

Kimura, G., Hashimoto, Y., Kitamura, Y., Yamaguchi, A., \& Koge, H. (2014). Middle Miocene swift migration of the TTT triple junction and rapid crustal growth in southwest Japan: A review. Tectonics, 33(7), 1219-1238. https://doi.org/10.1002/2014tc003531

Kita, S., \& Matsubara, M. (2016). Seismic attenuation structure associated with episodic tremor and slip zone beneath Shikoku and the Kii peninsula, southwestern Japan, in the Nankai subduction zone. Journal of Geophysical Research: Solid Earth, 121(3), 1962-1982. https:// doi.org/10.1002/2015jb012493

Koketsu, K., Miyake, H., Fujiwara, H., \& Hashimoto, T. (2008). Progress towards a Japan integrated velocity structure model and long-period ground motion hazard map. In Proceedings of the 14th world conference on earthquake engineering ( $\mathrm{p}$. S10).

Krischer, L., Megies, T., Barsch, R., Beyreuther, M., Lecocq, T., Caudron, C., \& Wassermann, J. (2015). Obspy: A bridge for seismology into the scientific python ecosystem. Computational Science \& Discovery, 8(1), 014003. https://doi.org/10.1088/1749-4699/8/1/014003

Kubo, A., Fukuyama, E., Kawai, H., \& Nonomura, K. (2002). NIED seismic moment tensor catalogue for regional earthquakes around Japan: Quality test and application. Tectonophysics, 356(1-3), 23-48. https://doi.org/10.1016/s0040-1951(02)00375-X

Kurihara, R., Obara, K., Takeo, A., \& Maeda, T. (2018). Migration of deep low-frequency tremor triggered by teleseismic earthquakes in the southwest Japan subduction zone. Geophysical Research Letters, 45(8), 3413-3419. https://doi.org/10.1002/2017gl076779

Lengliné, O., Frank, W. B., Marsan, D., \& Ampuero, J.-P. (2017). Imbricated slip rate processes during slow slip transients imaged by low-frequency earthquakes. Earth and Planetary Science Letters, 476, 122-131. https://doi.org/10.1016/j.epsl.2017.07.032

Lomax, A. (2005). A reanalysis of the hypocentral location and related observations for the great 1906 California earthquake. Bulletin of the Seismological Society of America, 95(3), 861-877. https://doi.org/10.1785/0120040141

Lomax, A. (2008). Location of the focus and tectonics of the focal region of the California earthquake of 18 April 1906. Bulletin of the Seismological Society of America, 98(2), 846-860. https://doi.org/10.1785/0120060405

Lowen, S., \& Teich, M. (2005). Fractal-based point processes. John Wiley \& Sons.

Maeda, T., \& Obara, K. (2009). Spatiotemporal distribution of seismic energy radiation from low-frequency tremor in western Shikoku, Japan. Journal of Geophysical Research, 114(B10). https://doi.org/10.1029/2008jb006043

Masuda, K., Ide, S., Ohta, K., \& Matsuzawa, T. (2020). Bridging the gap between low-frequency and very-low-frequency earthquakes. Earth Planets and Space, 72(1), 1-9. https://doi.org/10.1186/s40623-020-01172-8

Maury, J., Ide, S., Cruz-Atienza, V. M., \& Kostoglodov, V. (2018). Spatiotemporal variations in slow earthquakes along the Mexican subduction zone. Journal of Geophysical Research: Solid Earth, 123(2), 1559-1575. https://doi.org/10.1002/2017JB014690

Miyazawa, M., Brodsky, E. E., \& Mori, J. (2008). Learning from dynamic triggering of low-frequency tremor in subduction zones. Earth Planets and Space, 60(10), e17-e20. https://doi.org/10.1186/bf03352858

Nakajima, J., \& Hasegawa, A. (2016). Tremor activity inhibited by well-drained conditions above a megathrust. Nature Communications, 7(1), 1-7. https://doi.org/10.1038/ncomms13863

Nakajima, J., \& Uchida, N. (2018). Repeated drainage from megathrusts during episodic slow slip. Nature Geoscience, 11(5), 351-356. https://doi.org/10.1038/s41561-018-0090-z

NIED. (2019). National research institute for earth science and disaster resilience. https://doi.org/10.17598/nied.0003, Hi-net

Obara, K. (2002). Nonvolcanic deep tremor associated with subduction in southwest Japan. Science, 296(5573), 1679-1681. https://doi. org/10.1126/science.1070378

Obara, K. (2010). Phenomenology of deep slow earthquake family in southwest Japan: Spatiotemporal characteristics and segmentation. Journal of Geophysical Research: Solid Earth, 115(B8). https://doi.org/10.1029/2008jb006048

Obara, K., \& Hirose, H. (2006). Non-volcanic deep low-frequency tremors accompanying slow slips in the southwest Japan subduction zone. Tectonophysics, 417(1-2), 33-51. https://doi.org/10.1016/j.tecto.2005.04.013

Obara, K., Kasahara, K., Hori, S., \& Okada, Y. (2005). A densely distributed high-sensitivity seismograph network in Japan: Hi-net by national research institute for earth science and disaster prevention. Review of Scientific Instruments, 76(2), 021301. https://doi. org/10.1063/1.1854197

Obara, K., \& Kato, A. (2016). Connecting slow earthquakes to huge earthquakes. Science, 353(6296), 253-257. https://doi.org/10.1126/ science.aaf1512

Obara, K., Matsuzawa, T., Tanaka, S., Kimura, T., \& Maeda, T. (2011). Migration properties of non-volcanic tremor in Shikoku, southwest Japan. Geophysical Research Letters, 38(9). https://doi.org/10.1029/2011gl047110

Obara, K., Tanaka, S., Maeda, T., \& Matsuzawa, T. (2010). Depth-dependent activity of non-volcanic tremor in southwest Japan. Geophysical Research Letters, 37(13). https://doi.org/10.1029/2010gl043679

Ochi, T., Itaba, S., Koizumi, N., Takahashi, M., Matsumoto, N., Kitagawa, Y., et al. (2016). Short-term slow slip events in the Tokai area, the Kii peninsula and the Shikoku district, Japan (from May to October 2014). Report of the Coordinating Committee for Earthquake Prediction, 95, 225-264.

Okada, Y., Kasahara, K., Hori, S., Obara, K., Sekiguchi, S., Fujiwara, H., \& Yamamoto, A. (2004). Recent progress of seismic observation networks in Japan-Hi-net, f-net, k-net and kik-net. Earth Planets and Space, 56(8). https://doi.org/10.1186/bf03353076

Okamura, Y., \& Shishikura, M. (2020). New hypothesis to explain quaternary forearc deformation and the variety of plate boundary earthquakes along the Suruga-Nankai trough by oblique subduction of undulations on the Philippine Sea plate. Earth Planets and Space, 72 , 1-14. https://doi.org/10.1186/s40623-020-01183-5

Ozawa, S. (2017). Long-term slow slip events along the Nankai trough subduction zone after the 2011 Tohoku earthquake in Japan. Earth Planets and Space, 69(1), 56. https://doi.org/10.1186/s40623-017-0640-4

Peng, Z., \& Gomberg, J. (2010). An integrated perspective of the continuum between earthquakes and slow-slip phenomena. Nature Geoscience, 3(9), 599-607. https://doi.org/10.1038/ngeo940

Poiata, N., Satriano, C., Vilotte, J.-P., Bernard, P., \& Obara, K. (2016). Multiband array detection and location of seismic sources recorded by dense seismic networks. Geophysical Journal International, 205(3), 1548-1573. https://doi.org/10.1093/gji/ggw071

Poiata, N., Vilotte, J.-P., Bernard, P., Satriano, C., \& Obara, K. (2018). Imaging different components of a tectonic tremor sequence in southwestern Japan using an automatic statistical detection and location method. Geophysical Journal International, 213 (3), 2193-2213. https://doi.org/10.1093/gji/ggy070 
Rogers, G., \& Dragert, H. (2003). Episodic tremor and slip on the Cascadia subduction zone: The chatter of silent slip. Science, 300(5627), 1942-1943. https://doi.org/10.1126/science.1084783

Rousset, B., Bürgmann, R., \& Campillo, M. (2019). Slow slip events in the roots of the San Andreas Fault. Science advances, 5(2), eaav3274. https://doi.org/10.1126/sciadv.aav3274

Schwartz, S. Y., \& Rokosky, J. M. (2007). Slow slip events and seismic tremor at Circum-Pacific subduction zones. Reviews of Geophysics, 45(3). https://doi.org/10.1029/2006rg000208

Sekine, S., Hirose, H., \& Obara, K. (2010). Along-strike variations in short-term slow slip events in the southwest Japan subduction zone. Journal of Geophysical Research, 115(B9). https://doi.org/10.1029/2008jb006059

Shapiro, N. M., Campillo, M., Kaminski, E., Vilotte, J.-P., \& Jaupart, C. (2018). Low-frequency earthquakes and pore pressure transients in subduction zones. Geophysical Research Letters, 45(20), 11-083. https://doi.org/10.1029/2018gl079893

Shelly, D. R. (2009). Possible deep fault slip preceding the 2004 Parkfield earthquake, inferred from detailed observations of tectonic tremor. Geophysical Research Letters, 36(17). https://doi.org/10.1029/2009gl039589

Shelly, D. R. (2015). Complexity of the deep San Andreas Fault zone defined by cascading tremor. Nature Geoscience, 8(2), 145-151. https:// doi.org/10.1038/ngeo2335

Shelly, D. R., Beroza, G. C., \& Ide, S. (2007a). Complex evolution of transient slip derived from precise tremor locations in western Shikoku, Japan. Geochemistry, Geophysics, Geosystems, 8(10). https://doi.org/10.1029/2007gc001640

Shelly, D. R., Beroza, G. C., \& Ide, S. (2007b). Non-volcanic tremor and low-frequency earthquake swarms. Nature, $446(7133), 305-307$. https://doi.org/10.1038/nature05666

Shelly, D. R., Beroza, G. C., Ide, S., \& Nakamula, S. (2006). Low-frequency earthquakes in Shikoku, Japan, and their relationship to episodic tremor and slip. Nature, 442(7099), 188-191. https://doi.org/10.1038/nature04931

Shelly, D. R., \& Johnson, K. M. (2011). Tremor reveals stress shadowing, deep postseismic creep, and depth-dependent slip recurrence on the lower-crustal San Andreas Fault near Parkfield. Geophysical Research Letters, 38(13). https://doi.org/10.1029/2011gl047863

Song, T.-R. A., Helmberger, D. V., Brudzinski, M. R., Clayton, R. W., Davis, P., Pérez-Campos, X., \& Singh, S. K. (2009). Subducting slab ultra-slow velocity layer coincident with silent earthquakes in southern Mexico. Science, 324(5926), 502-506. https://doi.org/10.1126/ science. 1167595

Supino, M., Poiata, N., Festa, G., Vilotte, J.-P., Satriano, C., \& Obara, K. (2020). Self-similarity of low-frequency earthquakes. Scientific Reports, 10(1), 1-9. https://doi.org/10.1038/s41598-020-63584-6

Tang, C.-C., Peng, Z., Chao, K., Chen, C.-H., \& Lin, C.-H. (2010). Detecting low-frequency earthquakes within non-volcanic tremor in southern Taiwan triggered by the 2005 Mw8. 6 Nias earthquake. Geophysical Research Letters, 37(16). https://doi.org/10.1029/2010gl043918

Trugman, D. T., Wu, C., Guyer, R. A., \& Johnson, P. A. (2015). Synchronous low frequency earthquakes and implications for deep San Andreas Fault slip. Earth and Planetary Science Letters, 424, 132-139. https://doi.org/10.1016/j.epsl.2015.05.029

Ujiie, K., \& Kimura, G. (2014). Earthquake faulting in subduction zones: Insights from fault rocks in accretionary prisms. Progress in Earth and Planetary Science, 1(1), 7. https://doi.org/10.1186/2197-4284-1-7

Ujiie, K., Saishu, H., Fagereng, Å., Nishiyama, N., Otsubo, M., Masuyama, H., \& Kagi, H. (2018). An explanation of episodic tremor and slow slip constrained by crack-seal veins and viscous shear in subduction mélange. Geophysical Research Letters, 45(11), 5371-5379. https://doi.org/10.1029/2018gl078374

Walter, J. I., Schwartz, S. Y., Protti, J. M., \& Gonzalez, V. (2011). Persistent tremor within the northern Costa Rica seismogenic zone. Geophysical Research Letters, 38(1). https://doi.org/10.1029/2010gl045586

Wech, A. G., \& Creager, K. C. (2011). A continuum of stress, strength and slip in the Cascadia subduction zone. Nature Geoscience, 4(9), 624-628. https://doi.org/10.1038/ngeo1215

Wessel, P., Luis, J., Uieda, L., Scharroo, R., Wobbe, F., Smith, W., \& Tian, D. (2019). The generic mapping tools version 6. Geochemistry, Geophysics, Geosystems, 20(11), 5556-5564. https://doi.org/10.1029/2019gc008515

Yabe, S., \& Ide, S. (2014). Spatial distribution of seismic energy rate of tectonic tremors in subduction zones. Journal of Geophysical Research: Solid Earth, 119(11), 8171-8185. https://doi.org/10.1002/2014jb011383

Yamazaki, T., \& Okamura, Y. (1989). Subducting seamounts and deformation of overriding forearc wedges around Japan. Tectonophysics, 160(1-4), 207-229. https://doi.org/10.1016/0040-1951(89)90392-2 